\title{
A Computer Program to Determine the Specific Power of Prismatic- Core Reactors
}

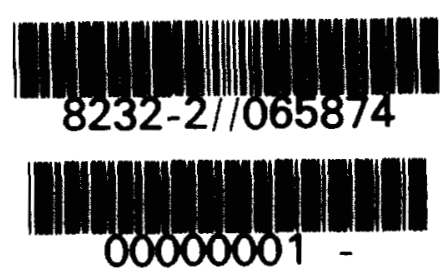

Dean Dobranich

\section{Prepared by}

Sandia National Laboratories

Albuquerque, New Mexico 87185 and Livermore, California 94550

for the United States Department of Energy

under Contract DE-AC04-76DP00789 
lssued oy Sandia National Laboratories. operated for the [Inited States Department of Energy by Sandia ('orporation.

NOTICE: This report was prepared as an account of work sponsored by an agency of the I nited states Govermment. Neither the I'nited States Govern ment nor ams ayency thereot. nor any of their emplosees, nor any of their cont ractors, subcontractors. or their emplosees. makes any warranty, exprest or implied, or assumes any legal liability or respomsibility for the accuracy

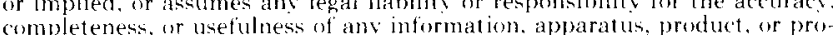
completenesis. or usefulness of any informatom, apparatus, product, or pro cess disclosed. "or represents that its use would mot infringe privately owned
rishts. Reference herein to any specific commercial product, process or rights. Reference herein to any specific commercial product, process. or
service by trade name. trademark. manufacturer, or otherwise. does not necessarily comstitute or imply its endorsement. recommendation, or favoring br the l'nited states fovernment, any agency therenf or any of their cont ractors or subcontractors. The views and opinons expressed herein do not necessirily state or reflect those of the Inited States Government. any agency hereot or anv of their contracoss or subcont ractors.

\author{
Printed in the linited Sitates of America \\ Available from \\ National Technical Jrformation Service \\ I.S. Department of Commerce \\ 528 i Port Roval Road \\ Springfiedd. VA 22)161 \\ Nols price code \\ Printed (o) X:: A0 \\ Microfiche copy: A0l
}


SAND87-0735

Unlimited Release

Printed May 1987
Distribution

Category UC-80

A COMPUTER PROGRAM TO DETERMINE THE SPECIFIC POWER OF PRISMATIC-CORE REACTORS

\author{
Dean Dobranich \\ Advanced Nuclear Power Safety Division \\ Sandia National Laboratories \\ Albuquerque, New Mexico 87185
}

\begin{abstract}
A computer program has been developed to determine the maximum specific power for prismatic-core reactors as a function of maximum allowable fuel temperature, core pressure drop, and coolant velocity. The prismatic-core reactors consist of hexagonally shaped fuel elements grouped together to form a cylindrically shaped core. A gas coolant flows axially through circular channels within the elements, and the fuel is dispersed within the solid element material either as a composite or in the form of coated pellets. Different coolant, fuel, coating, and element materials can be selected to represent different prismatic-core concepts. The computer program allows the user to divide the core into any arbitrary number of axial levels to account for different axial power shapes. An option in the program allows the automatic determination of the core height that results in the maximum specific power. The results of parametric specific power calculations using this program are presented for various reactor concepts.
\end{abstract}





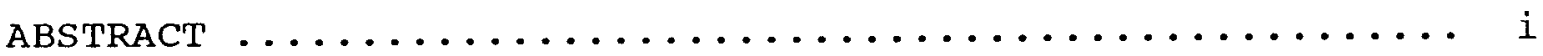

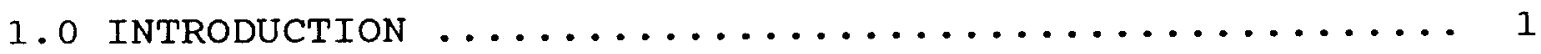

2.0 COMPUTER PROGRAM DESCRIPTION $\ldots \ldots \ldots \ldots \ldots \ldots \ldots \ldots \ldots$

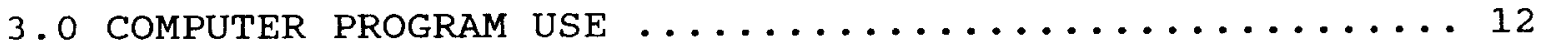

4.0 PARAMETRIC CALCULATIONS .................. 17

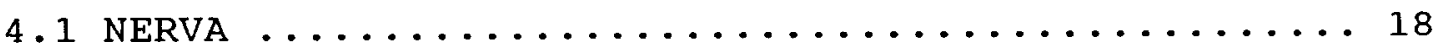

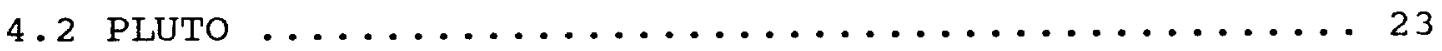

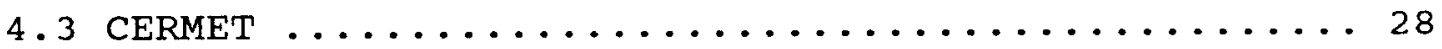

4.4 SUMMARY OF PARAMETRIC CALCULATIONS ........... 30

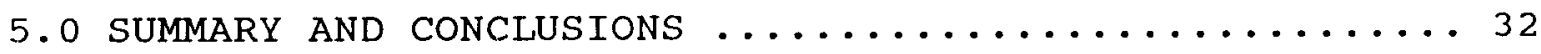

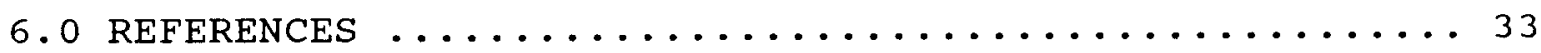

APPENDIX - COMPUTER PROGRAM LISTING 


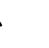




\section{0 INTRODUCTION}

The prismatic-core reactors consist of hexagonally shaped fuel elements grouped together to form a cylindrically shaped core. A gas coolant flows axially through circular channels within the elements, and the fuel is dispersed within the solid element (matrix) material either as a composite or in the form of coated spherical pellets. Figure 1.0.1 provides a diagram of a typical fuel element for a prismatic core along with examples of the coated pellets and composite fuel forms.

The specific power is defined as the amount of power that can be produced per unit of fuel mass (power/mass). Thus, higher values of specific power result in less massive reactor cores for a given power level. Two constraints that must be considered when determining the maximum specific power that a reactor core can achieve are criticality and heat removal. To satisfy the criticality constraint, the size, composition, and geometry of the core must be such that criticality can be achieved over the entire reactor lifetime. Satisfying this constraint dictates the mass of fuel required. To satisfy the heat removal constraint, the amount of power produced must be such that it can be removed without exceeding the maximum allowed core temperatures or the maximum allowed coolant velocity or core pressure drop.

A computer program has been written to calculate the core power for any given fuel mass and core length. Used in conjunction with criticality calculations, this program allows one to determine the specific power for a prismatic-core reactor. The program includes approximate models to account for the thermal resistance associated with the coolant, matrix, coating, and fuel. Different coolant, matrix, coating, and fuel materials can be selected to represent different prismatic-core concepts. The computer program allows the user to divide the core into any arbitrary number of axial levels to account for different axial power shapes. Also, an option in the code allows the automatic determination of the core height that results in the maximum specific power.

This report contains a description of the models used in the computer program along with some examples of the application of the program. 


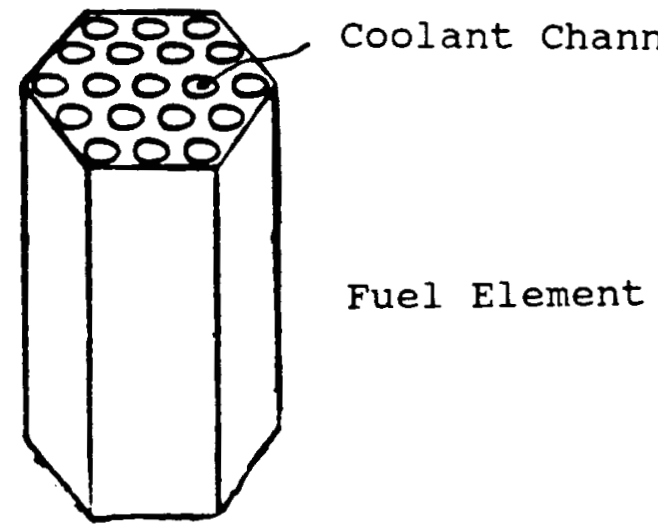

FUEL FORMS

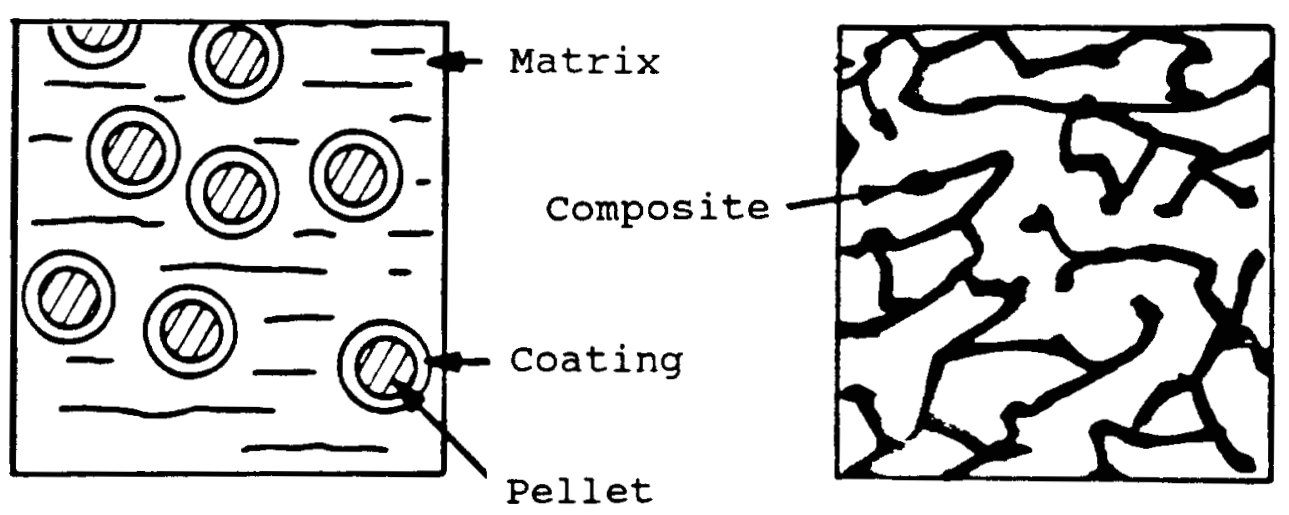

Figure 1.0.1 Typical Prismatic-Core Fuel Element 


\subsection{COMPUTER PROGRAM DESCRIPTION}

The program was written to allow the user to specify the material for the coolant, matrix, coating, and fuel. Presently, properties for the following core materials are available:

1 - uranium carbide

2 - uranium dioxide

3 - uranium boride

4 - reactor grade graphite

5 - boron carbide

6 - beryllium oxide

7 - zirconium carbide

8 - tungsten

9 - molybdenum

Also, two gases are available for the coolant:

1 - helium

2 - hydrogen

The thermophysical properties for these materials are built into the program as a function of temperature. These properties were taken from References 1 through 4 ; curve fits (linear, logarithmic, or power) to the data were made to allow easy evaluation of the properties at any temperature. The property functions are provided in the appendix, which contains a FORTRAN listing of the entire program. Figures 2.0 .1 through 2.0 .5 are graphs of the resulting property functions. The ideal gas law was used to calculate the coolant density as a function of pressure and temperature.

A cross-sectional view of a prismatic-core fuel element is provided in Figure 2.0.6. In this example, there are seven channels within the element. The variable $s$ denotes the maximum conduction length within the element; this represents the greatest distance that heat must travel from the fuel to the channel wall. If the fuel is in the form of coated pellets dispersed uniformly within the matrix, a pellet is assumed to reside at this location to provide a conservative (worst case) estimate of the fuel maximum temperature. The input variable $S$ can be calculated for $N$ uniformly spaced channels using the following equation:

$$
\mathrm{S}=\mathrm{D} /\left(2 \mathrm{~N}_{\mathrm{d}} \cos ^{\mathrm{e}}(30)\right)-\mathrm{d}_{\mathrm{C}} / 2-\mathrm{d}_{\mathrm{p}} / 2-t
$$

where: $D=$ hexagon flat-to-flat width,

$\mathrm{N}_{\mathrm{d}}=$ number of channels across the element diagonal, $e=1$ if $N=1 ; e=2$ for $N>1$,

$d_{c}=$ channel diameter,

$\mathrm{d}_{\mathrm{p}}^{\mathrm{c}}=$ pellet diameter, and

If the fuel is in the form of a composite, the fuel is dispersed within the matrix material and there are no pellets or 
coating; $d_{p}$ and $t$ would be set equal to zero in this case. For uniformly spaced channels, Table 2.0.1 provides the value of $\mathrm{N}_{\mathrm{d}}$ for various values of the number of channels per element, $\mathrm{N}$. If the channels are not uniformly spaced, $S$ must be calculated in a manner appropriate with the spacing.

Table 2.0.1 Number of Diagonal Channels

$\begin{array}{rl}\mathrm{N} & \mathrm{N}_{\mathrm{d}} \\ 1 & 1 \\ 7 & 3 \\ 19 & 5 \\ 37 & 7 \\ 61 & 9\end{array}$

Specific power, defined as the total power produced in the core divided by the total fuel mass, is determined by the core criticality constraints and by the core heat transfer and hydraulic constraints. The total core power, $\mathrm{P}$, is given by:

$$
P=m c_{p}\left(T_{O}-T_{I}\right)
$$

with: $m=\rho \mathrm{VA}$

where: $\mathrm{m}=$ core mass flow rate,

$\rho=$ coolant density,

$\mathrm{V}=$ coolant velocity,

$A=$ core flow area,

$\mathrm{C}_{\mathrm{p}}=$ coolant average specific heat,

$\mathrm{T}_{\mathrm{O}}^{\mathrm{p}}=$ core outlet coolant temperature, and

$\mathrm{T}_{\mathrm{I}}=$ core inlet coolant temperature.

For a given fuel element geometry (i.e., number of channels, channel diameter, and hexagon width), only the velocity in Equation (2) is unknown $\left(\mathrm{T}_{\mathrm{I}}\right.$ and $\mathrm{T}_{\mathrm{O}}$ are input variables). The computer program calculates the maximum coolant velocity such that a prescribed maximum fuel, coating, or matrix temperature is not exceeded (heat transfer limit) or a maximum core pressure drop (hydraulic limit) is not exceeded. Also, a maximum-allowed coolant Mach number can be established as a limiting criteria.

Based on the specified core pressure, and coolant inlet and outlet temperatures, the coolant sonic speed is calculated at the core inlet and outlet. Using the maximum of the inlet and outlet sonic speeds and the specified maximum allowed Mach number, the coolant velocity (and hence, core mass flow rate) is determined. Equation (2) is then used to calculate the core power based on this velocity. However, if this calculated power results in core temperatures or a core pressure drop that exceeds 
specified limits, the velocity is reduced and a new power and associated core temperatures and pressure drop are determined. The velocity is reduced until the limits are no longer exceeded.

For any arbitrary axial power profile, the axial location at which the maximum core temperature occurs is not known.

Therefore, the computer program allows the core to be divided into any number of equally spaced axial levels. Relative power factors for each level are then specified to define the axial power profile. (A program option allows the user to specify either a flat or cosine power profile in which the relative power factors are automatically calculated.) Equation (2) is used to determine the coolant temperature at the ends of the axial levels. The average specific heat for each level is calculated as the algebraic average of that level's inlet and outlet specific heats. The average specific heat must be determined iteratively with Equation (2) because the outlet temperature for each level is unknown.

Using the average coolant temperature for each level, the coolant properties are evaluated from which the Reynolds and Prandtl numbers are determined. The velocity for each core level, $v_{z}$, is determined based on continuity such that $v_{z}=$ $\mathrm{m} / \rho \mathrm{A}$ where $\mathrm{m}$ is the core mass flow rate and $\rho$ is that level's coolant density. (If a value of zero is specified as the number of core levels, then the coolant properties and velocity for the heat transfer calculations are based on the core exit temperature.) Now, enough information is available to determine the temperature drop from the coolant, through the matrix and coating, to the fuel. (If the fuel is in the form of a composite, the temperature drop associated with the coating and the fuel pellet is not applicable.)

To determine the temperature drop from the coolant to the channel wall, the Taylor equation [4] for the coolant heat transfer coefficient, $h$, is used. This equation is:

$$
\mathrm{h}=0.023 \mathrm{Ck} / \mathrm{d}_{\mathrm{C}} \operatorname{Re}^{0.8} \mathrm{Pr}^{0.4}
$$

with,

$$
\begin{aligned}
& \mathrm{C}=\left(\mathrm{T}_{\mathrm{W}} / \mathrm{T}_{\mathrm{C}}\right) \mathrm{E} \\
& \mathrm{E}=\left(1.59 \mathrm{~d}_{\mathrm{C}} / \mathrm{x}-0.57\right)
\end{aligned}
$$

where: $\mathrm{k}=$ coolant conductivity,

$\mathrm{d}_{\mathrm{c}}=$ channel diameter,

Ré = Reynold's number,

$\operatorname{Pr}=$ Prandtl's number,

$\mathrm{T}_{\mathrm{W}}=$ wall temperature,

$\mathrm{T}_{\mathrm{C}}=$ coolant bulk temperature, and

$\mathrm{x}=$ distance from channel entrance.

This equation is for turbulent flow in circular channels and is a function of the channel wall temperature; thus, it must be solved iteratively with Newton's law of cooling, given by: 


$$
P=h A_{W}\left(T_{W}-T_{C}\right)
$$

where: $A_{W}=$ total channel wall area.

If the core is divided into axial levels, then Equation (4) is solved for each level. (This equation does not account for aerodynamic heating effects that would be expected to occur at very high coolant velocities.)

Next, the temperature drop across the matrix material of the element $\left(\Delta \mathrm{T}_{\mathrm{m}}\right)$ is determined. As already mentioned, the

variable $s$ represents the maximum distance that heat must travel from the fuel to the channel wall. An estimate of the

temperature drop across this distance can be made by using the conduction relation for heat flow in a hollow cylinder of inside radius equal to one-half the channel diameter and outside radius equal to the inside radius plus the distance $S$. Thus,

$$
\Delta \mathrm{T}_{\mathrm{m}}=\left(\mathrm{P}_{\mathrm{z}} / \mathrm{N}\right) \ln \left[\left(2 \mathrm{~S}+\mathrm{d}_{\mathrm{C}}\right) / \mathrm{d}_{\mathrm{C}}\right] /\left(2 \pi \Delta z \mathrm{k}_{\mathrm{m}}\right)
$$

where: $\mathrm{P}_{z}=$ core axial level power,

$\mathrm{N}^{\mathrm{Z}}=$ number of coolant channels,

$S=$ maximum conduction length,

$\mathrm{d}_{\mathrm{C}}=$ channel diameter,

$\Delta \mathbf{z}=$ axial level length, and

$\mathrm{k}_{\mathrm{m}}=$ matrix thermal conductivity.

This equation has been derived assuming that the matrix thermal conductivity is constant. A crude estimate of an average thermal conductivity for the matrix is found by first solving Equation (5) using $\mathrm{k}_{\mathrm{m}}$ evaluated at the previously calculated (Equations (3) and (4)) channel wall temperature. Then, a first guess for the maximum matrix temperature, $\mathrm{T}_{\mathrm{m}}$, is calculated as $\mathrm{T}_{\mathrm{W}}+\Delta \mathrm{T}_{\mathrm{m}}$. Now, $\mathrm{k}_{\mathrm{m}}$ is evaluated at the algebraic average of $\mathrm{T}_{\mathrm{w}}$ and $\mathrm{T}_{\mathrm{m}}$, and Equation (5) is solved again to provide a better estimate of $\mathrm{T}_{\mathrm{m}}$. If the fuel is in the form of a composite, $\mathrm{k}_{\mathrm{m}}$ is determined as a volume average of the fuel and matrix conductivities.

If pellet fuel is used, the temperature drop across the coating and the pellet must next be calculated. The temperature drop across the coating, $\Delta \mathrm{T}_{\mathrm{C}}$, is given by:

$$
\Delta \mathrm{T}_{\mathrm{c}}=\left(\mathrm{P}_{\mathrm{z}} / \mathrm{N}_{\mathrm{p}, \mathrm{z}}\right) \mathrm{t} /\left[2 \pi \mathrm{d}_{\mathrm{p}} \mathrm{k}_{\mathrm{c}}\left(\mathrm{d}_{\mathrm{p}} / 2+\mathrm{t}\right)\right]
$$

where: $\mathrm{P}_{\mathrm{Z}}=$ core axial level power,

$$
\begin{aligned}
\mathrm{N}_{\mathrm{p}, \mathrm{z}} & =\text { number of fuel pellets per core level, } \\
\mathrm{d}_{\mathrm{p}} & =\text { pellet diameter, and } \\
\mathrm{k}_{\mathrm{c}}^{\mathrm{p}} & =\text { coating thermal conductivity. }
\end{aligned}
$$

The temperature drop from the center of the spherical fuel pellet to the coating inside surface, $\Delta \mathrm{T}_{\mathrm{p}}$, is given by: 


$$
\Delta \mathrm{T}_{\mathrm{p}}=\mathrm{P}_{\mathrm{z}} / \mathrm{N}_{\mathrm{p}, \mathrm{z}} /\left(4 \pi \mathrm{d}_{\mathrm{p}} \mathrm{k}_{\mathrm{p}}\right)
$$

where: $k_{\mathrm{p}}=$ pellet thermal conductivity.

The next task is to determine the pressure drop from the core inlet to the core outlet. This is just the sum of the pressure drops across all core levels. The pressure drop for a core level, $\Delta \mathrm{p}_{\mathrm{z}}$, is calculated using:

$$
\Delta \mathrm{p}_{\mathrm{z}}=\mathrm{f} \Delta \mathrm{z} / \mathrm{d}_{\mathrm{C}}(\rho / 2) \mathrm{v}_{\mathrm{z}}^{2}
$$

with: $f=0.184 \mathrm{Re}^{-0.2} \mathrm{Pr}^{-0.6}$

The core pressure specified in the input is assumed to be the core inlet pressure. The pressure for each level (which is used in the calculation of the coolant density) is taken as the pressure at the level inlet based on the pressure drop for the preceding level. Thus, $p_{i+7}=p_{i}-\Delta p_{i}$. The subscripts refer to the pressure for tevel $i+1$ and the preceding level $i$.

Although this computer program can be used for any prismatic-core reactor, it was originally developed to perform parametric calculations for the NERVA reactor [5]. It therefore contains provisions to account for the effects of internal support structure within the core on the core flow rate and pressure drop.

NERVA fuel elements are grouped into clusters; each cluster contains six fueled elements and one centrally located unfueled element. Some of the clusters have central unfueled elements that contain a moderating material such as $\mathrm{ZrH}_{2}$; these clusters are referred to as moderated clusters and the elements in these clusters are referred to as moderated elements. The central elements in the moderated clusters contain an inner can and can holes that could be used to provide flow paths for coolant. The unmoderated clusters contain an inner and outer can in the central element that could also be used for coolant flow. Figure 2.0 .7 shows a diagram of the two types of clusters.

Two support structure cooling options are available in the program for the NERVA reactor. In one option, coolant first flows through the central elements to provide cooling of the support structure. The coolant then turns and flows through the fueled elements of the core. Thus, two core coolant passes are made and the pressure drop associated with each pass is calculated. The program user can also specify that the coolant makes only one core pass; i.e., the support structure and fueled elements are treated as parallel flow paths. For this option, the program calculates the additional coolant flow rate needed for support structure cooling assuming the pressure drops across both flow paths are equal. For the single-pass option, the input parameters describing the central element geometry can be neglected without effecting the specific power calculations. 


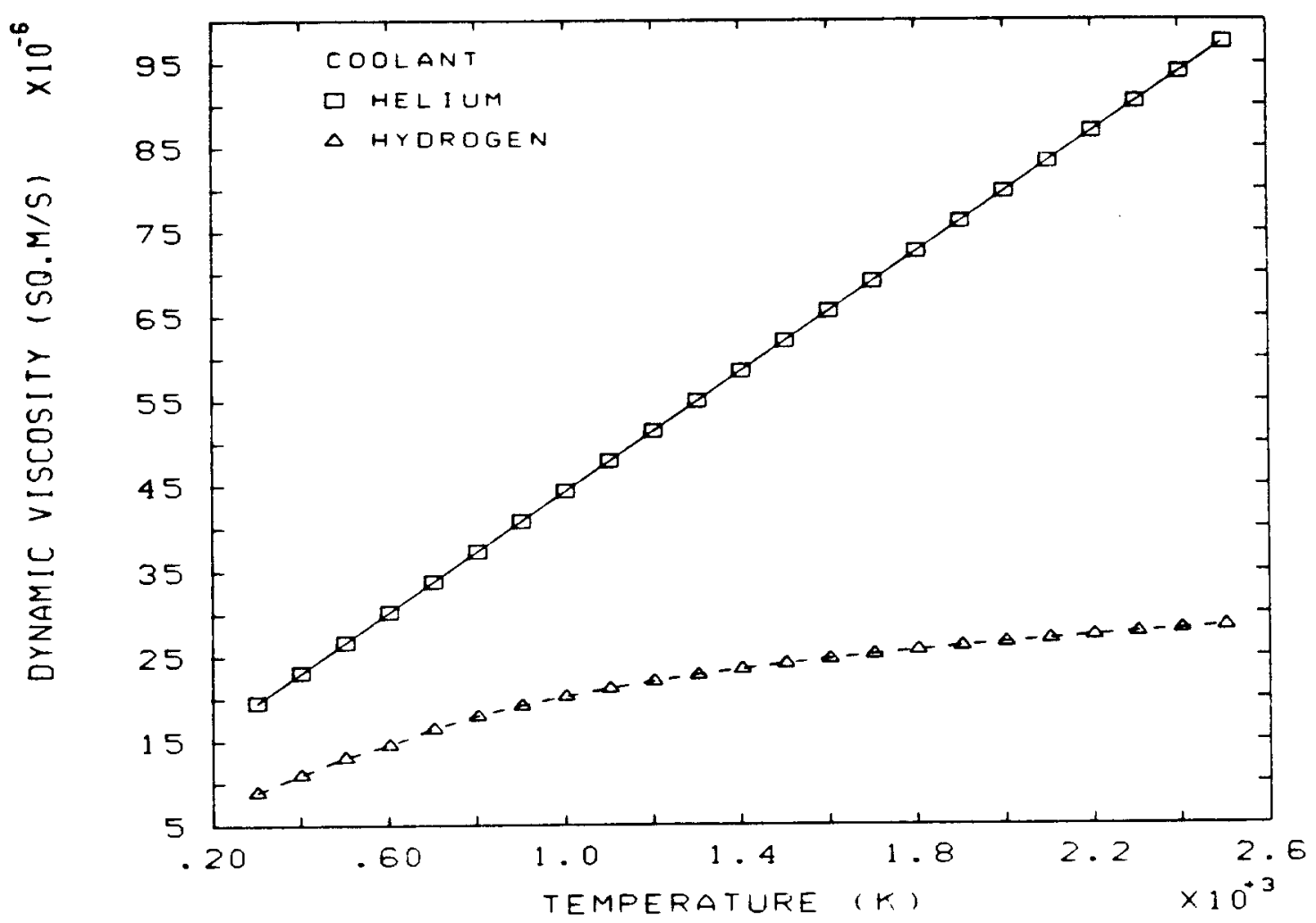

Figure 2.0.1 Coolant Dynamic Viscosity

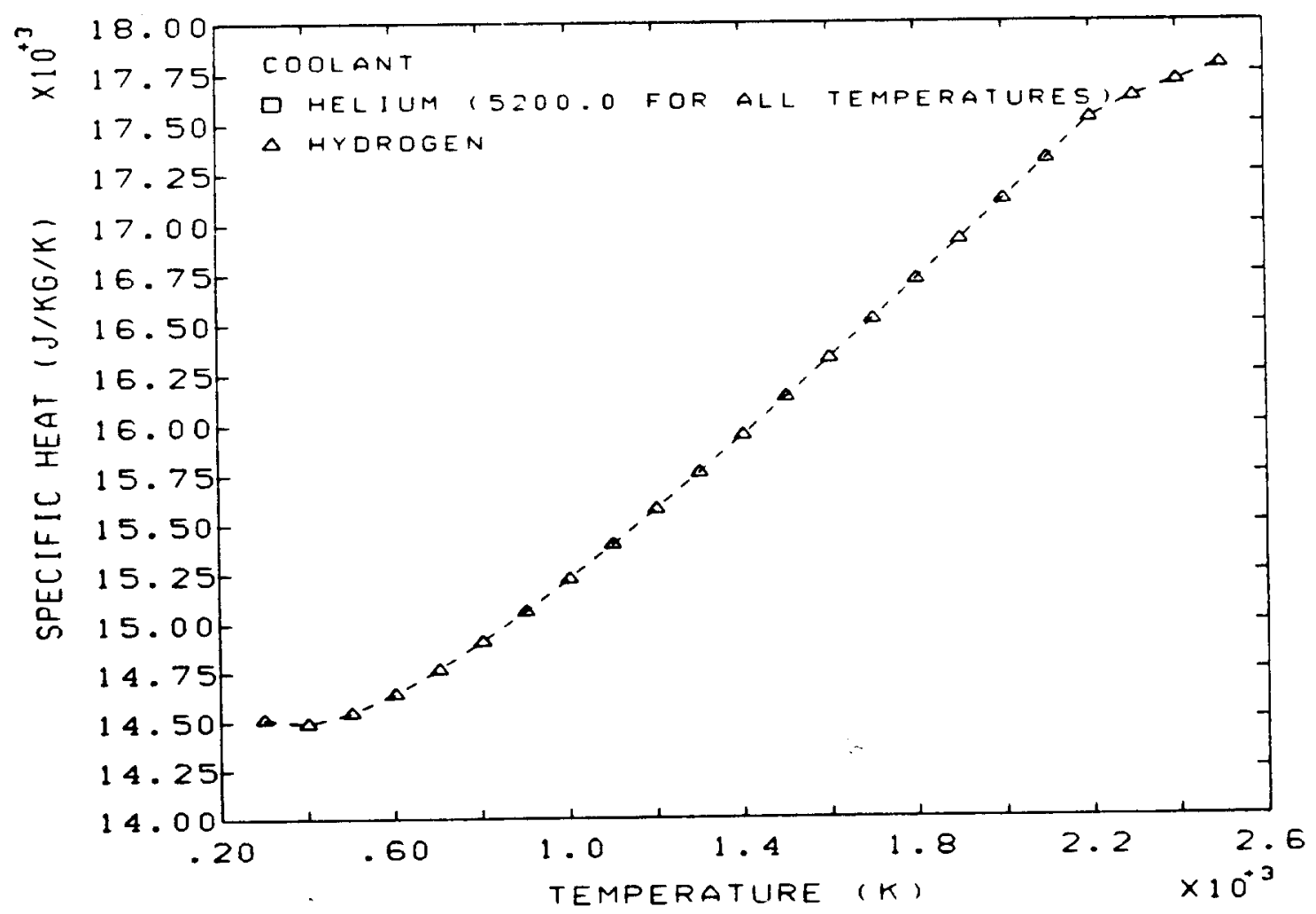

Figure 2.0.2 Coolant Specific Heat 


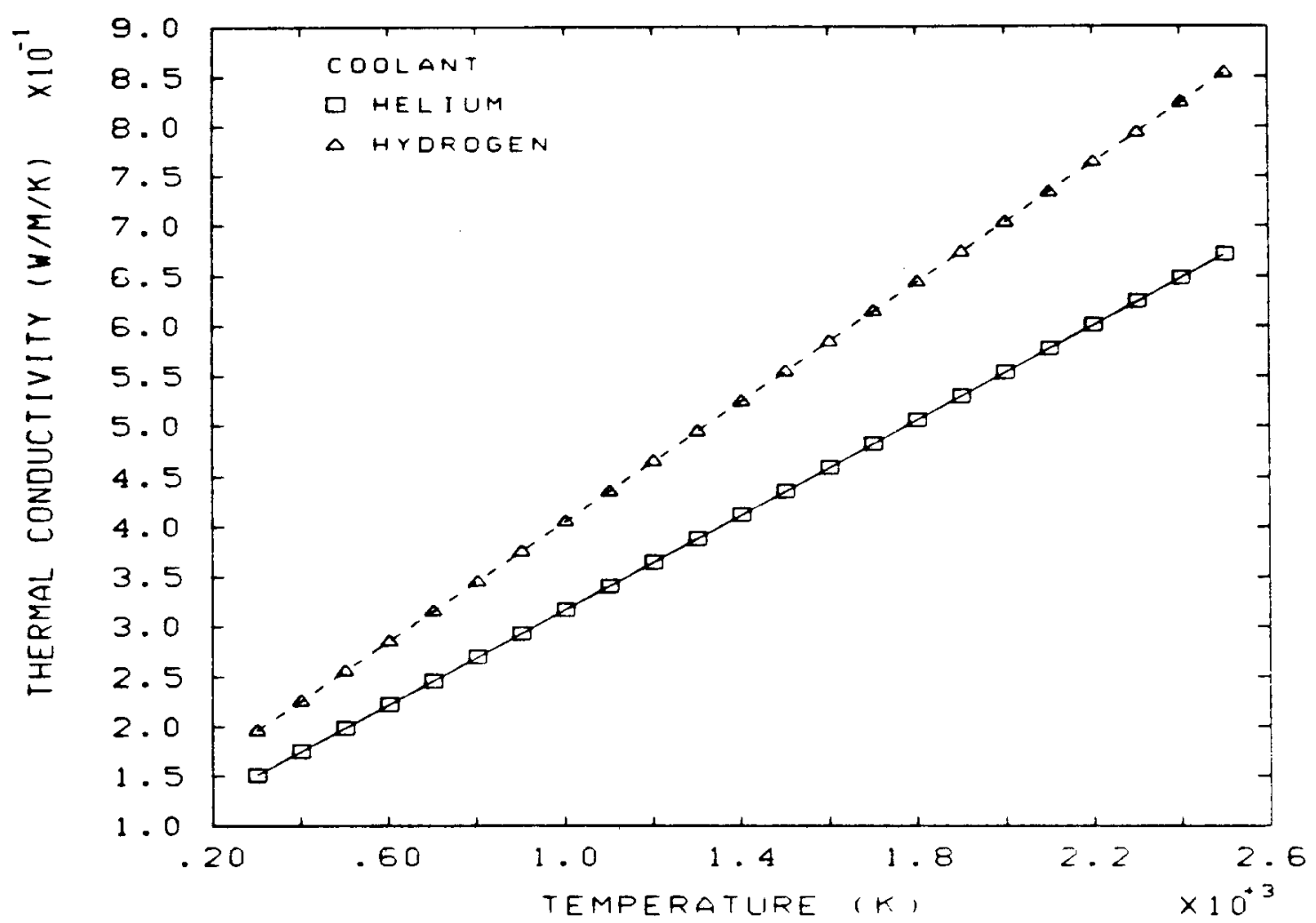

Figure 2.0.3 Coolant Thermal Conductivity

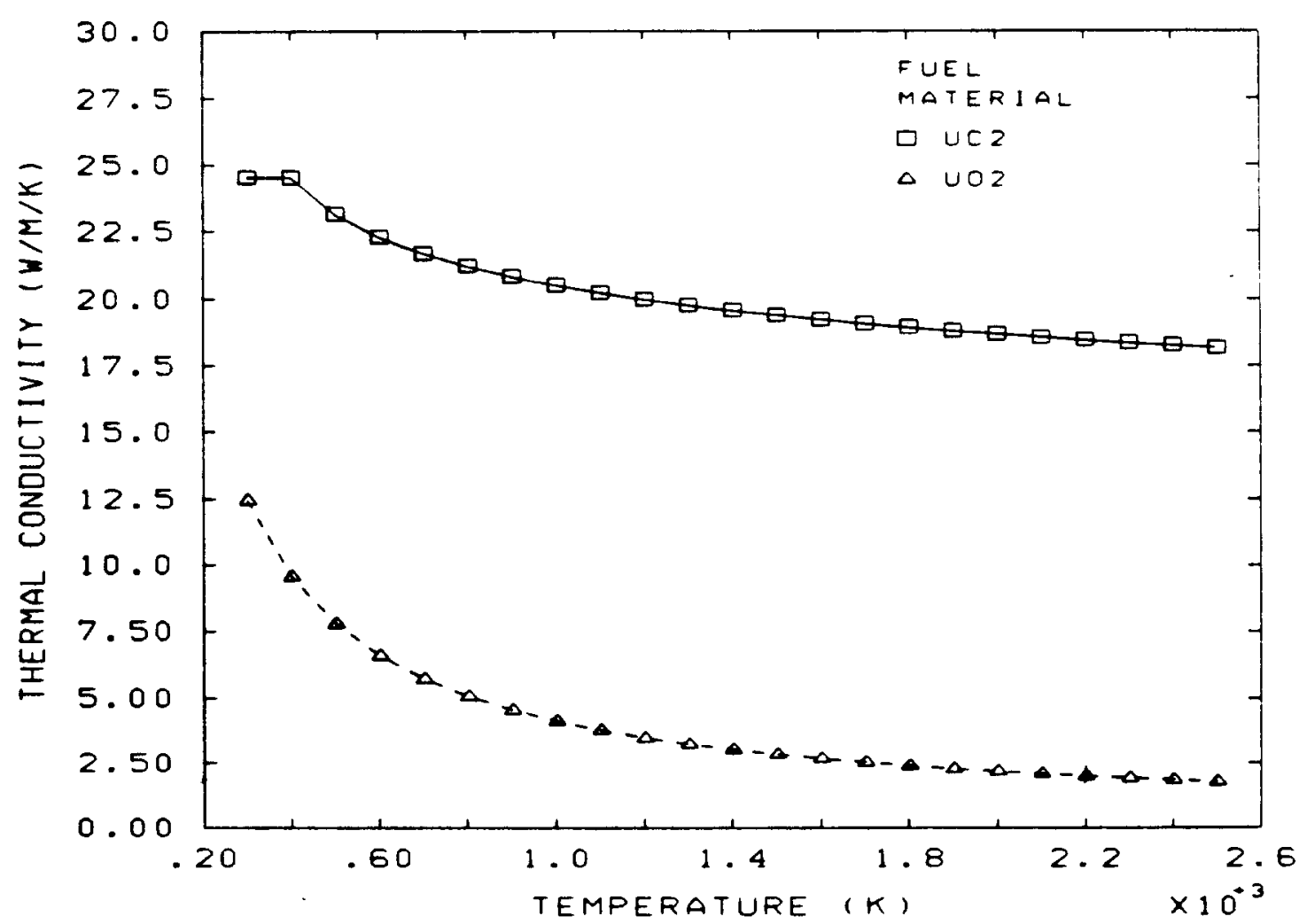

Figure 2.0.4 Fuel Thermal conductivity 


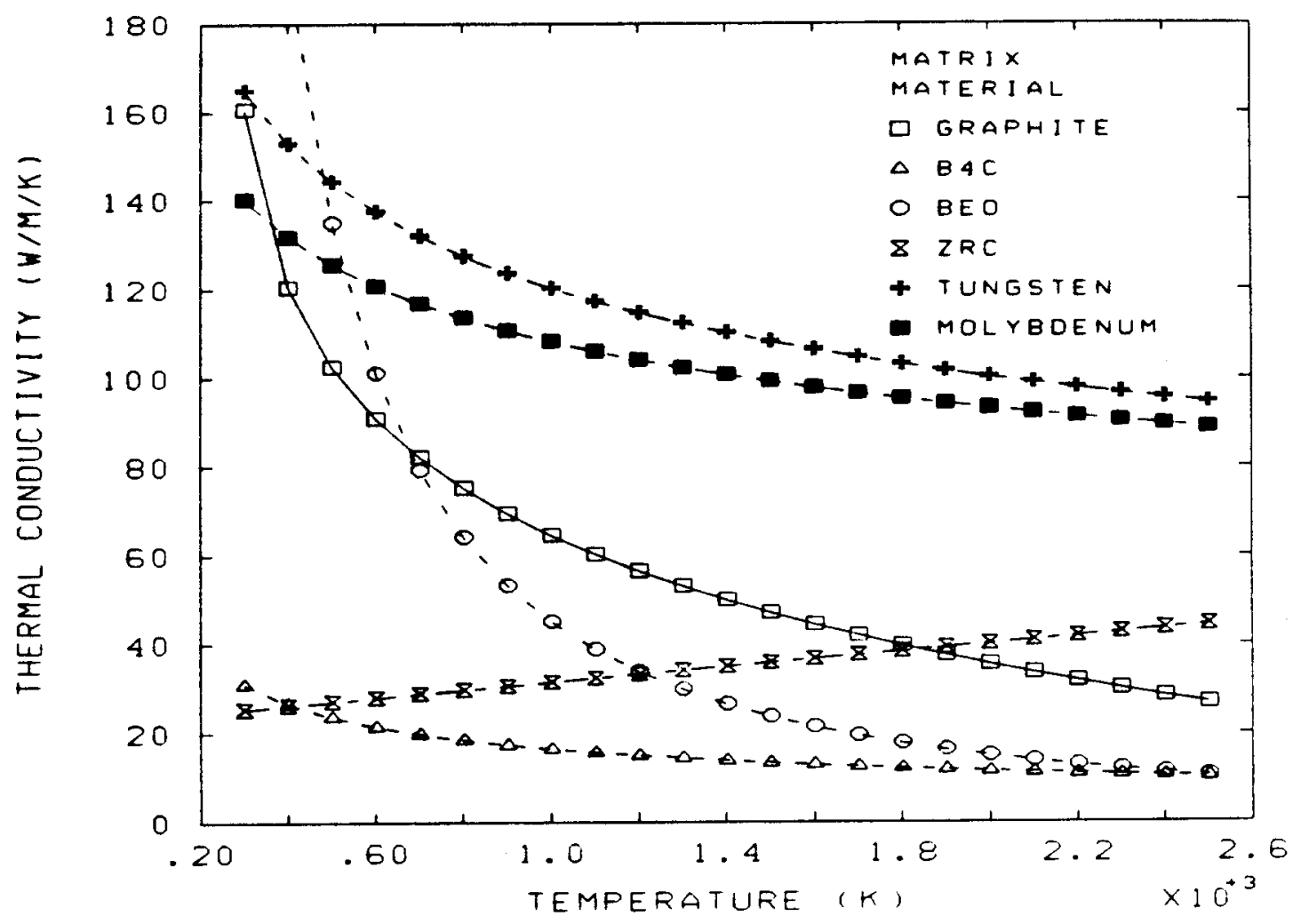

Figure 2.0.5 Matrix Thermal Conductivity

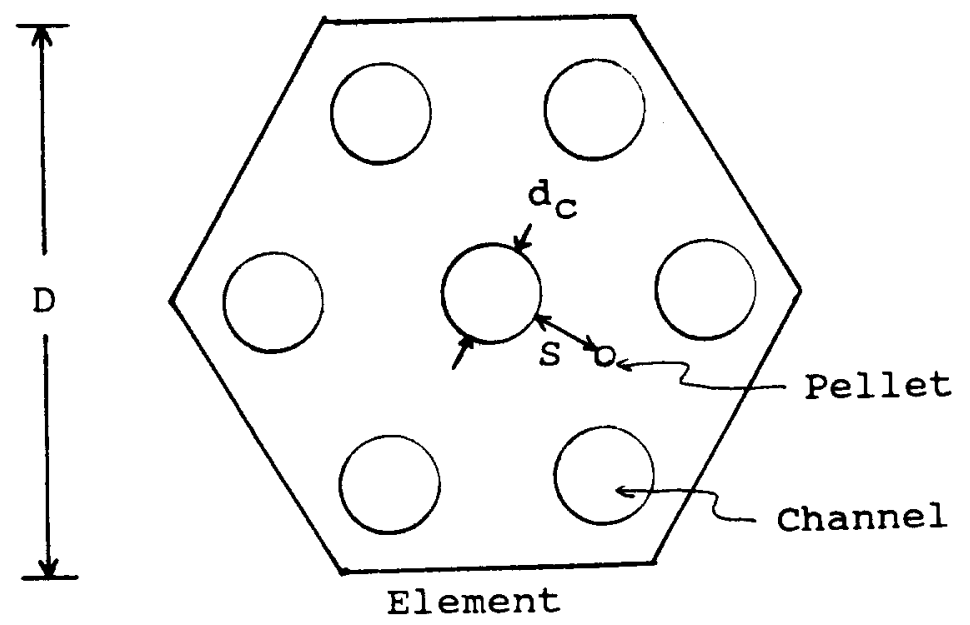

Figure 2.0.6 Fuel Element Cross-Sectional View 

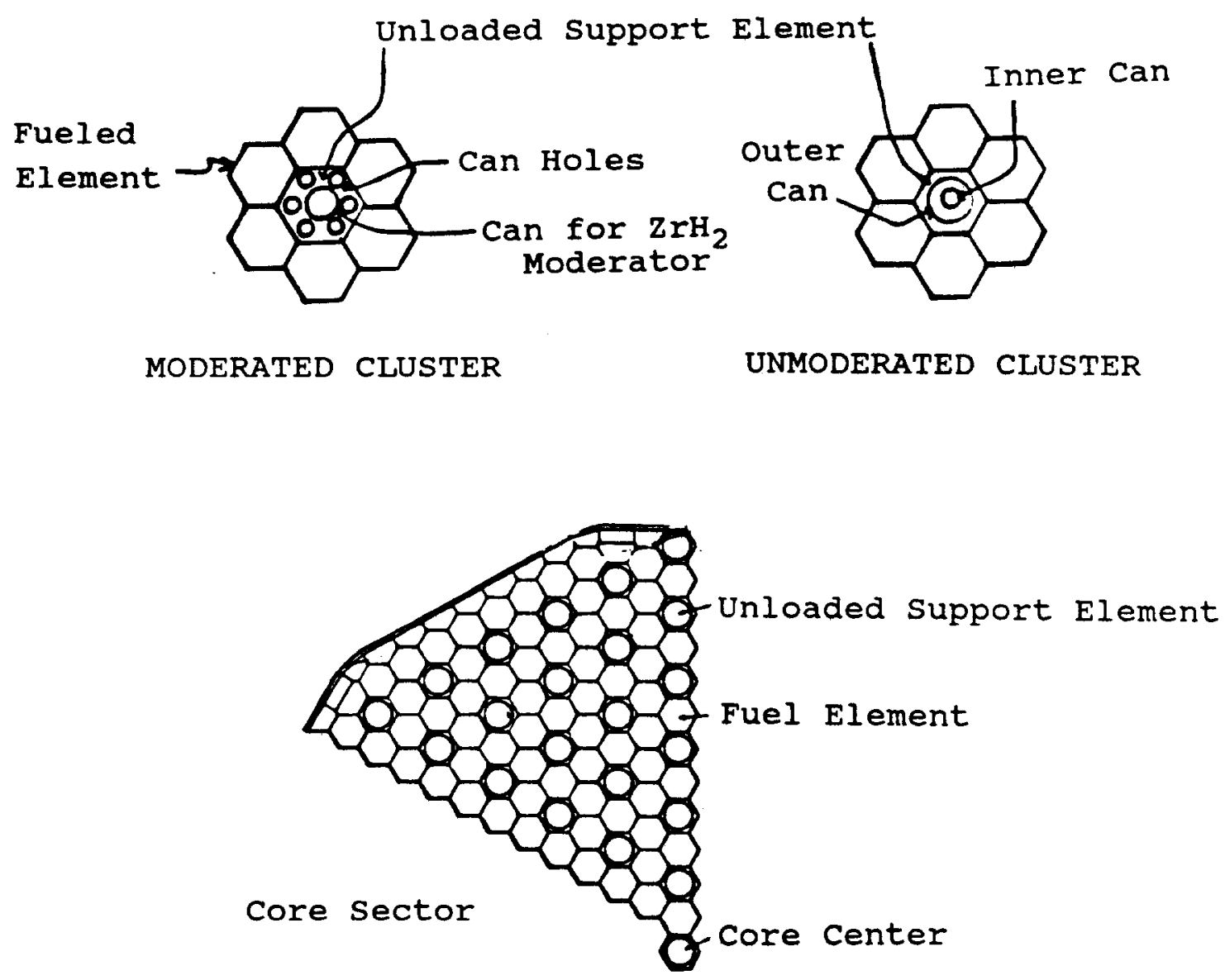

Figure 2.0.7 Cluster Configurations 


\section{O COMPUTER DROGRAM USE}

This section is included to provide an explanation of the use and interpretation of the program input and output. An annotated example input listing is included in Table 3.0.1; the annotations provide a concise description of the required input variables. The items marked with a "*" can be set to a value of one if the coolant makes only a single pass of the core and the total core power is not of interest. As mentioned in the previous section, the specific power is not affected by these variables.

Table 3.0.1 Example Input Listing

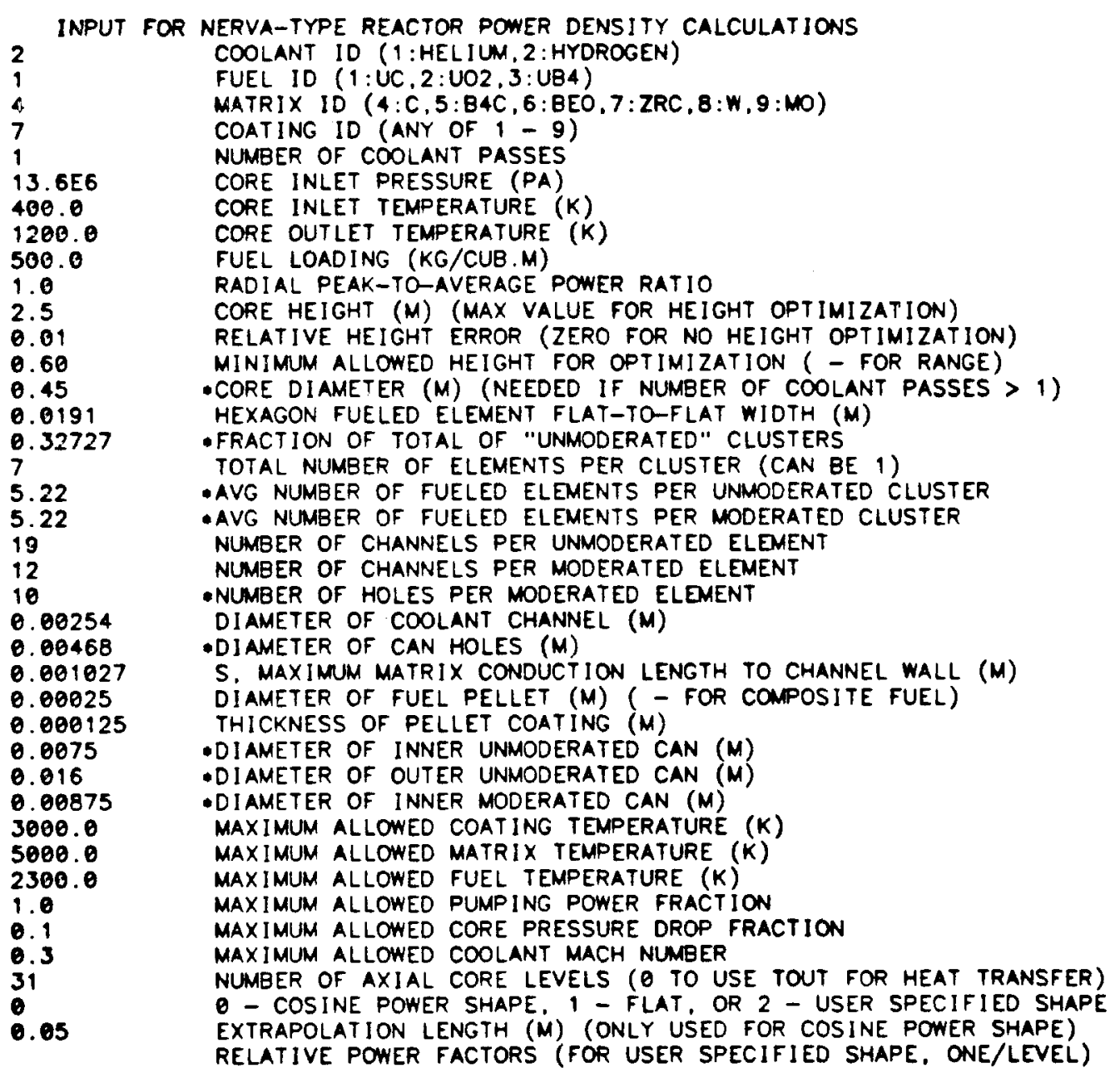

- parameter can be set to one if number of passes is one 
The specific power can be determined for any specified core height; or, if a nonzero value for the "relative height error" is entered, the program will automatically determine the core height that results in the maximum specific power. To use this option, a minimum and maximum core height must be entered to provide an interval in which the search for the maximum height is conducted. Also, if the minimum core height is entered as a negative number, the program will determine the specific power for a range ( 15 values) of core heights between the minimum and maximum height values.

As mentioned in sections 1.0 and 2.0 , the specific power is determined such that specified maximum core temperatures, pressure drop, and Mach number are not exceeded. The maximum core pressure drop is specified in the input as a maximum allowed core pressure drop fraction. This is defined as the maximum allowed core pressure drop divided by the core inlet pressure. Likewise, the maximum allowed coolant Mach number is defined as the maximum allowed coolant velocity divided by the coolant sonic velocity. Also, a maximum allowed pumping power can be imposed; this is defined as the maximum allowed pumping power for coolant flow through the core divided by the core power. (The core power is a function of the core diameter input variable.)

The number of axial core levels can be specified. If zero is chosen, the core is not subdivided and the heat transfer calculations are based on the coolant properties at the core outlet and the pressure drop calculation is based on the coolant properties evaluated at the coolant average temperature. Any power shape can be imposed on the core. If a cosine or flat power profile is desired, the program will automatically determine the relative power factors based on the number of axial levels selected. For the cosine profile, an axial extrapolation length can be specified. This is the distance outside the core where the neutron flux vanishes. If the diameter of the fuel pellet is specified as a negative number, the fuel is assumed to be in the form of a composite of the fuel and matrix materials. If this option is selected, the temperature drops across tle pellet and the coating are not applicable. The maximum conduction length, $s$, can be determined using Equation (1) of Section 2.0.

Table 3.0.2 provides the final output of the program for the example input problem. For this problem, the optimum core height was found to be $0.63 \mathrm{~m}$ corresponding to a specific power of 32.6 MW $/ \mathrm{kg}$. Besides the specific power, other parameters of interest are included in the output such as pressure drops and pumping powers. The output also consists of the core temperatures as a function of axial position. This output is displayed graphically in Figure 3.0.1. This figure shows that the maximum fuel temperature $(2300 \mathrm{~K})$ occurs at a core elevation of about $0.35 \mathrm{~m}$. This figure also shows that the largest temperature drops occur between the coolant and the channel wall and between the wall and the outside surface of the fuel coating. 
Table 3.0.2 Example Program Output

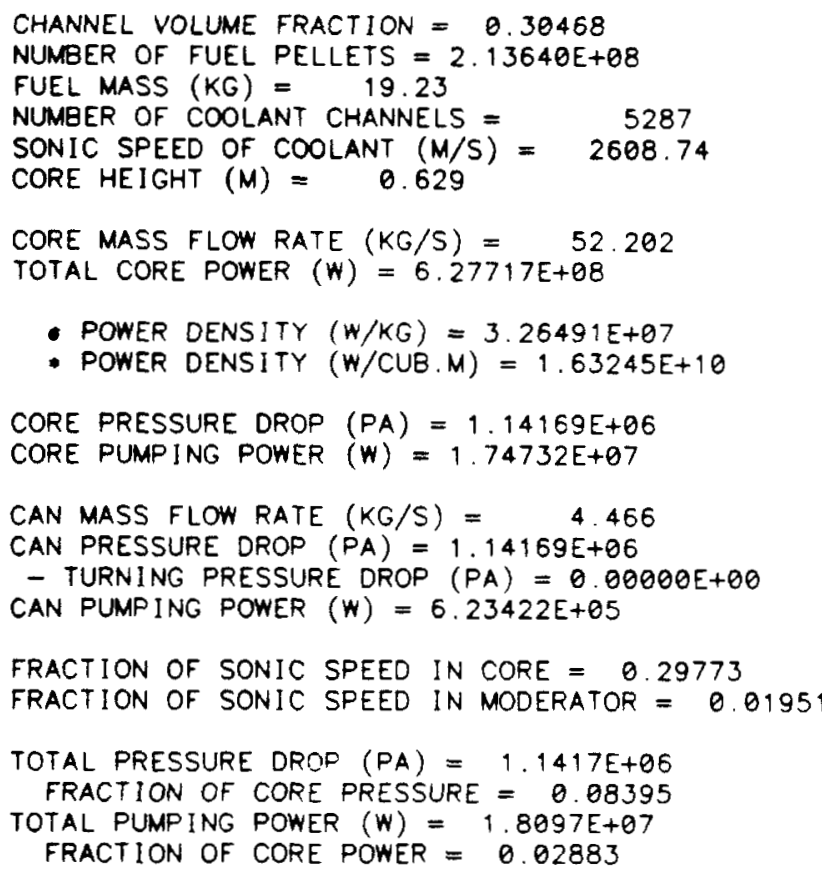

As an additional item of interest, the example problem was repeated using a flat axial power profile instead of a cosine profile. With the flat profile, the maximum specific power was found to be $37.9 \mathrm{MW} / \mathrm{kg}$ with an optimum core height of $0.54 \mathrm{~m}$. This demonstrates the advantage that can be gained by flattening of the axial power profile. (The program also allows the specification of a radial peak-to-average power ratio as a simple means of accounting for the effect of a radial power distribution.)

As a final example of the program use, the example problem was repeated with the number of coolant core passes specified as two. This situation is representative of the original NERVA core. Table 3.0 .3 shows the output for this case. Because two core passes are made, the core pressure drop is larger than for the single-pass case. The specific powers for the two cases are about the same, however. The reason for this is that the coolant velocity in the single-pass case was limited by the Mach number restriction; therefore, the advantage of the lower core pressure drop could not be realized. 
Table 3.0 .3 Output for Two-Pass Case

CHANNEL VOLUME FRACTION $=0.30468$

NUMBER OF FUEL PELLETS $=2.10906 \mathrm{E}+08$

FUEL MASS (KG) $=18.98$

MUMBER OF COOLANT CHANNELS = 5287

SONIC SPEED OF COOLANT $(M / S)=2608.74$

CORE HEIGHT (M) $=0.621$

CORE MASS FLOW RATE (KG/S) $=50.648$

TOTAL CORE POWER $(W)=6.09027 E+08$

- power deNSITy $(W / K G)=3.20875 E+07$

- power density (W/CUB.M) $=1.60438 E+10$

CORE PRESSURE DROP $(P A)=1.06567 E+86$

CORE PUMPING POWER $(W)=1.57627 E+07$

CAN MASS FLOW RATE (KG/S) $=50.648$

CAN PRESSURE DROP (PA) $=2.54894 E+05$

- TURNING PRESSURE DROP (PA) $=1.38169 E+05$

CAN PUMPING POWER $(W)=1.57149 E+06$

FRACTION OF SONIC SPEED IN CORE $=0.28720$

FRACTION OF SONIC SPEED IN MODERATOR $=0.25986$

TOTAL PRESSURE DROP (PA) $=1.3206 E+86$

FRACTION OF CORE PRESSURE $=0.09710$

TOTAL PUMPING POWER $(W)=1.7334 E+07$

FRACTION OF CORE POWER $=0.02846$ 


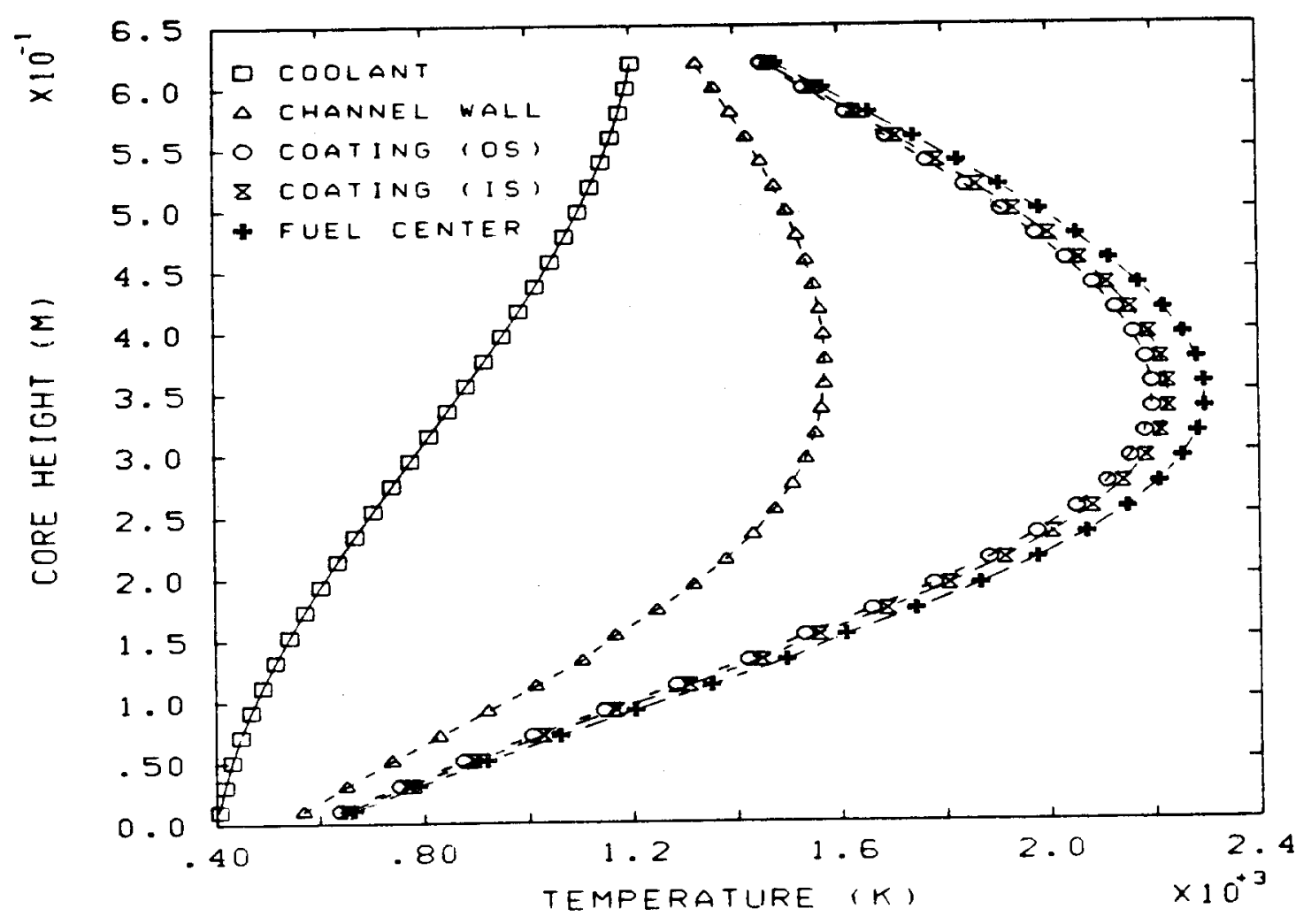

Figure 3.0.1 Core Temperatures 


\section{0 PARAMETRIC CALCULATIONS}

To demonstrate the application of the specific power computer program, parametric calculations were performed for three different prismatic-core reactor concepts: (1) NERVA derivative, (2) PLUTO derivative, and (3) CERMET derivative. Three variations of the NERVA concept and three variations of the PLUTO concept were included in the parametric calculations. Table 4.0.1 lists the assumed criteria used for the specific power calculations for all concepts. The pressure drop for all calculations was based on a single pass of the hydrogen coolant. The effects of changing the maximum fuel temperature, pressure drop fraction, and Mach number were investigated and are discussed later in this section.

Table 4.0.1 Assumed Criteria

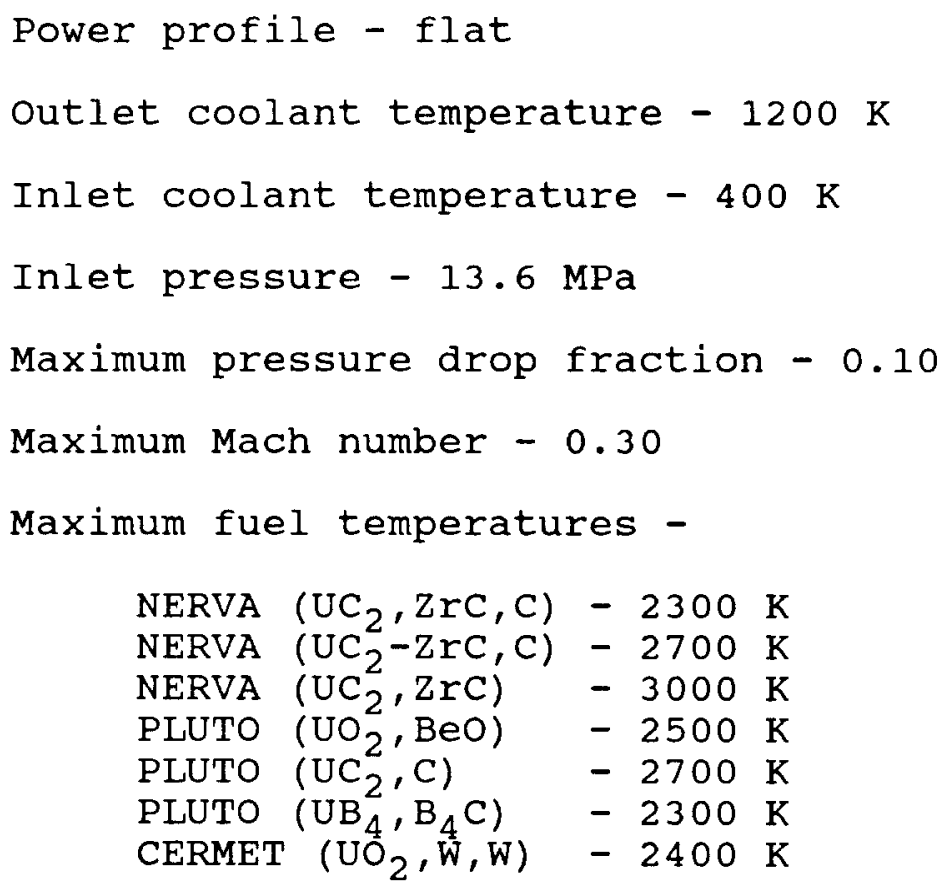

The symbols in parentheses indicate the core materials. The first material listed is the fuel, the second material is the fuel coating, and the last material is the element or matrix material that the fuel is imbedded in. If the core is made of a composite of fuel and matrix material, no coating material is needed and only two materials are listed.

The specific power for a given concept was determined as a function of the fuel loading and the core height (length). The fuel loading is defined as the mass of fuel material per unit volume of solid element (i.e., the volume of the element minus the volume of the coolant channels). The fuel loading and core length are treated parametrically because their final values depend on reactor criticality considerations. 


\title{
4.1 NERVA
}

Table 4.1.1 presents the pertinent geometric data that was used for the specific power calculations for the NERVA concepts. It is not necessary to specify a core diameter because specific power is independent of this parameter. (Recall that specific power is defined as the total power divided by the total fuel mass; both the total power and the total fuel mass are proportional to the square of the core diameter.)

Table 4.1.1 NERVA Geometric Data

\author{
Hexagon flat-to-flat width $-0.0191 \mathrm{~m}$ \\ Channel diameter - $0.00254 \mathrm{~m}$ \\ Number of channels/element - 19 \\ Fuel pellet diameter - $0.00025 \mathrm{~m}$ \\ Coating thickness - $0.000125 \mathrm{~m}$
}

Figure 4.1 .1 shows the results of the NERVA specific power calculations for $\mathrm{ZrC}$ coated $\mathrm{UC}_{2}$ pellet fuel in a graphite matrix. These curves show that a peak specific power occurs for a core length between about 0.55 and $0.65 \mathrm{~m}$, depending on the fuel loading. To the left of the peak, the specific power is limited by the maximum fuel temperature limit (i.e., heat transfer limited); to the right of the peak, the specific power is limited by the pressure drop or Mach number limit (i.e., hydraulic limited). Therefore, to increase the specific power in the heat transfer limited region, it is necessary to improve the heat transfer characteristics of the core by increasing the channel wall area, by using materials with higher thermal conductivity, or by increasing the maximum allowed fuel temperature. To increase the specific power in the hydraulic-limited region, it is necessary to improve the flow characteristics of the core by increasing the channel hydraulic diameter, by increasing the maximum allowed Mach number, or by increasing the maximum allowed pressure drop.

Figure 4.1.2 illustrates the effect of increasing the maximum allowed fuel temperature. The peak is shifted to a smaller core length and the specific powers to the left of the peak are improved. Increasing the temperature limit, however, has no effect on the specific powers to the right of the peak because there, the specific powers are hydraulic limited. 
Figure 4.1 .3 shows the effect of changing the maximum allowed Mach number and pressure drop fraction. Increasing the Mach number to 0.4 without also increasing the pressure drop fraction has no effect on the specific power because the specific power is limited by the pressure drop restriction. Increasing only the pressure drop fraction without increasing the Mach number has a small effect over most of the hydraulic-limited region. However, further increase in the pressure drop limit would not change the specific power because of the Mach number restriction. To get any significant benefit in the hydraulic-limited region, it is necessary to increase both the Mach number and pressure drop limits. For example, increasing the pressure drop fraction to 0.5 , with no Mach number restriction, results in a peak specific power of 54.0 $\mathrm{MW} / \mathrm{kg}$. This peak occurs at a core length of $0.86 \mathrm{~m}$ and an exit Mach number of 0.62 .

Figure 4.1.4 shows the specific power for a variation of the NERVA concept. The core geometry information is the same as for the previous concept but the core is made from a composite of the $\mathrm{UC}_{2}-\mathrm{ZrC}$ fuel and graphite matrix materials. Because the conduction resistances associated with a fuel pellet and coating are removed, the heat transfer characteristics of the composite core are improved. Also, the maximum allowed fuel temperature is higher for the composite, offering a further advantage over the pellet fuel. However, specific power is improved only in the heat transfer limited region. The specific power in the hydraulic-limited region remains the same as for the pellet fuel concept. Thus, the advantages of the composite core can be obtained only by using a very short core (for this particular core geometry).

Figure 4.1 .5 shows the specific power for a third NERVA concept. The core for this concept is a $U C_{2}$ fuel, ZrC matrix composite. The higher maximum allowed temperature for this composite offers improved specific powers, but again, only for short cores. Pressure drop and Mach number constraints obviate any improvement for longer cores. 


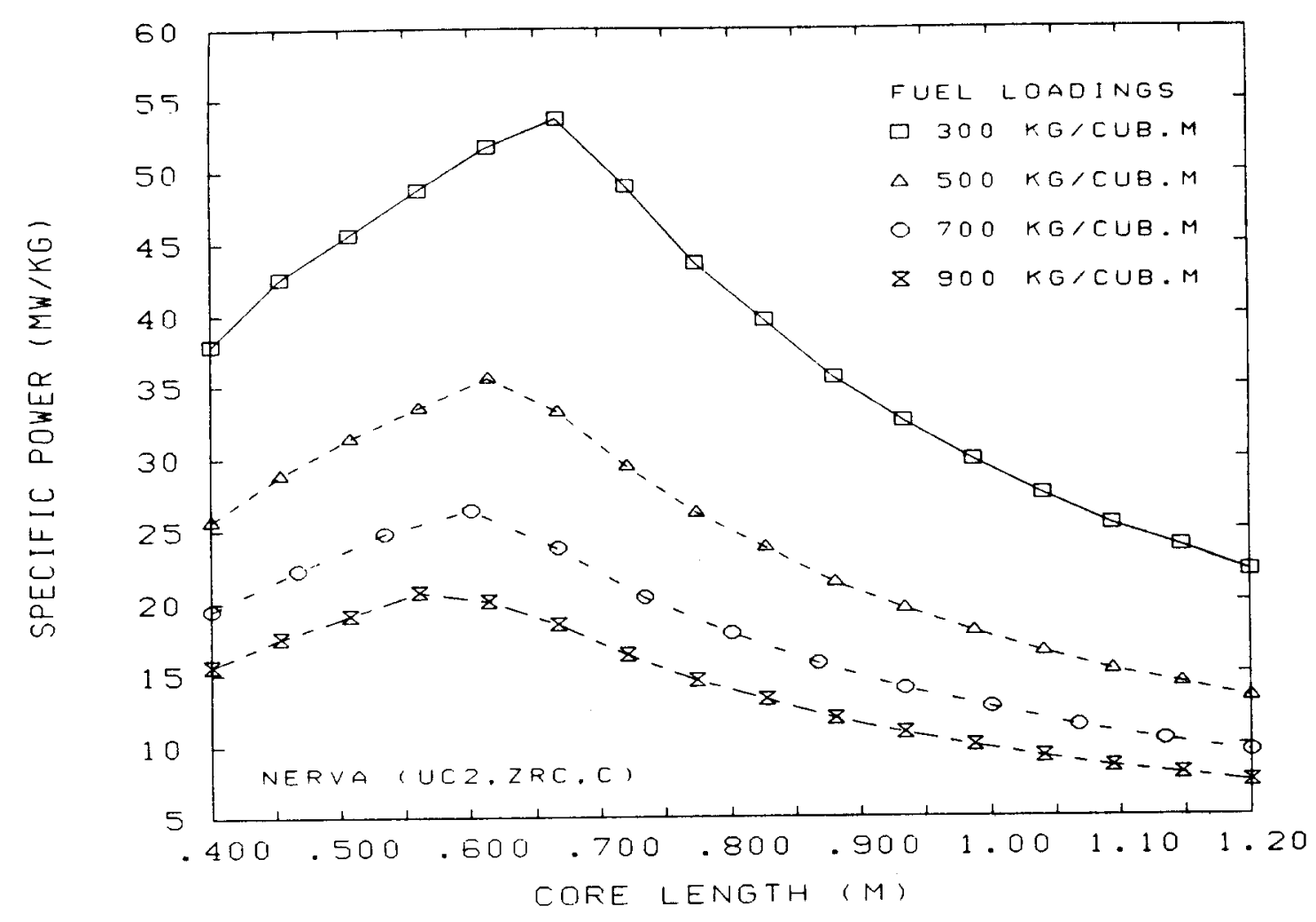

Figure 4.1.1 Specific Powers for NERVA Concept (Pellet Fuel)

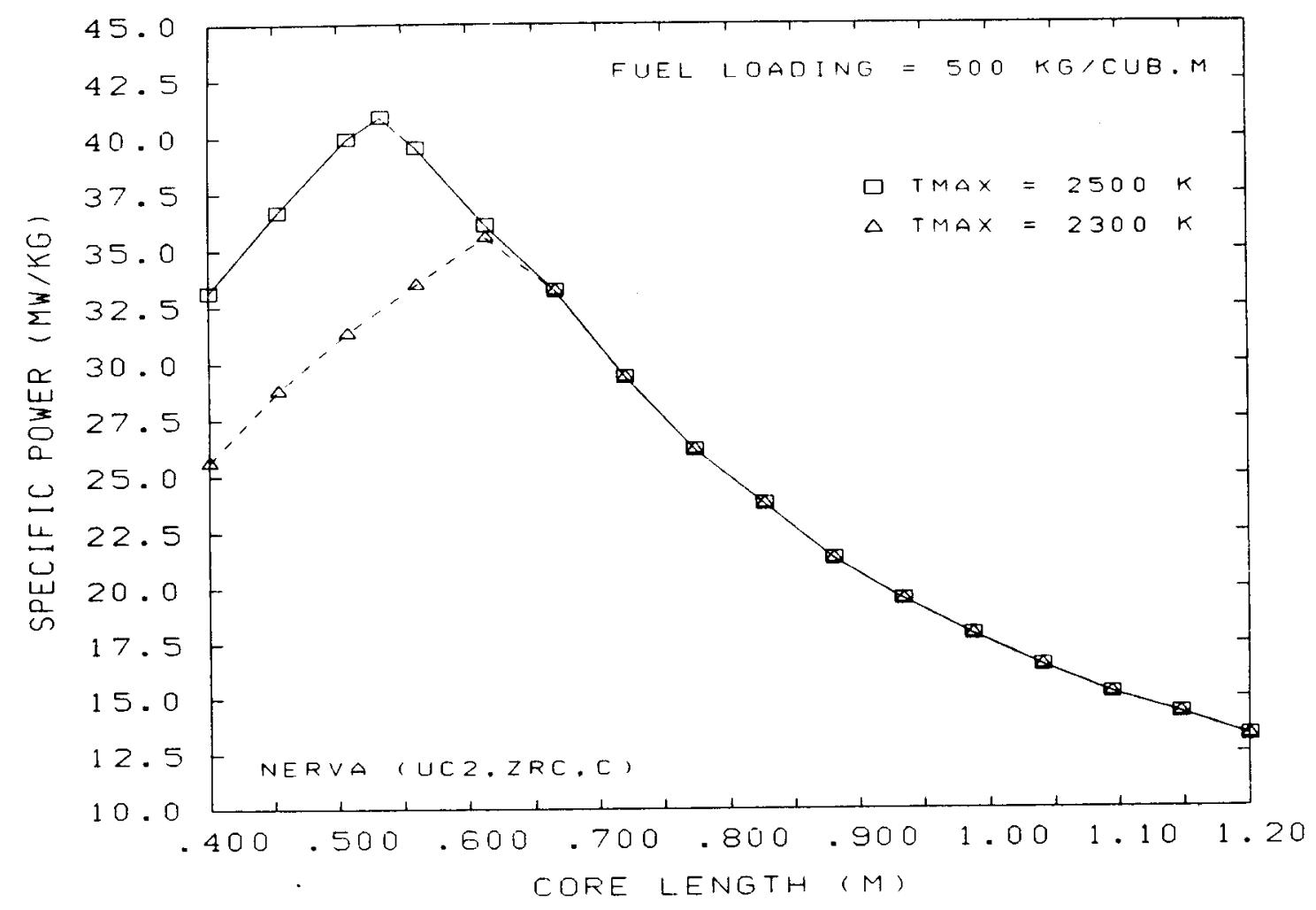

Figure 4.1.2 Effect of Maximum Fuel Temperature Limit on Specific Power (NERVA) 


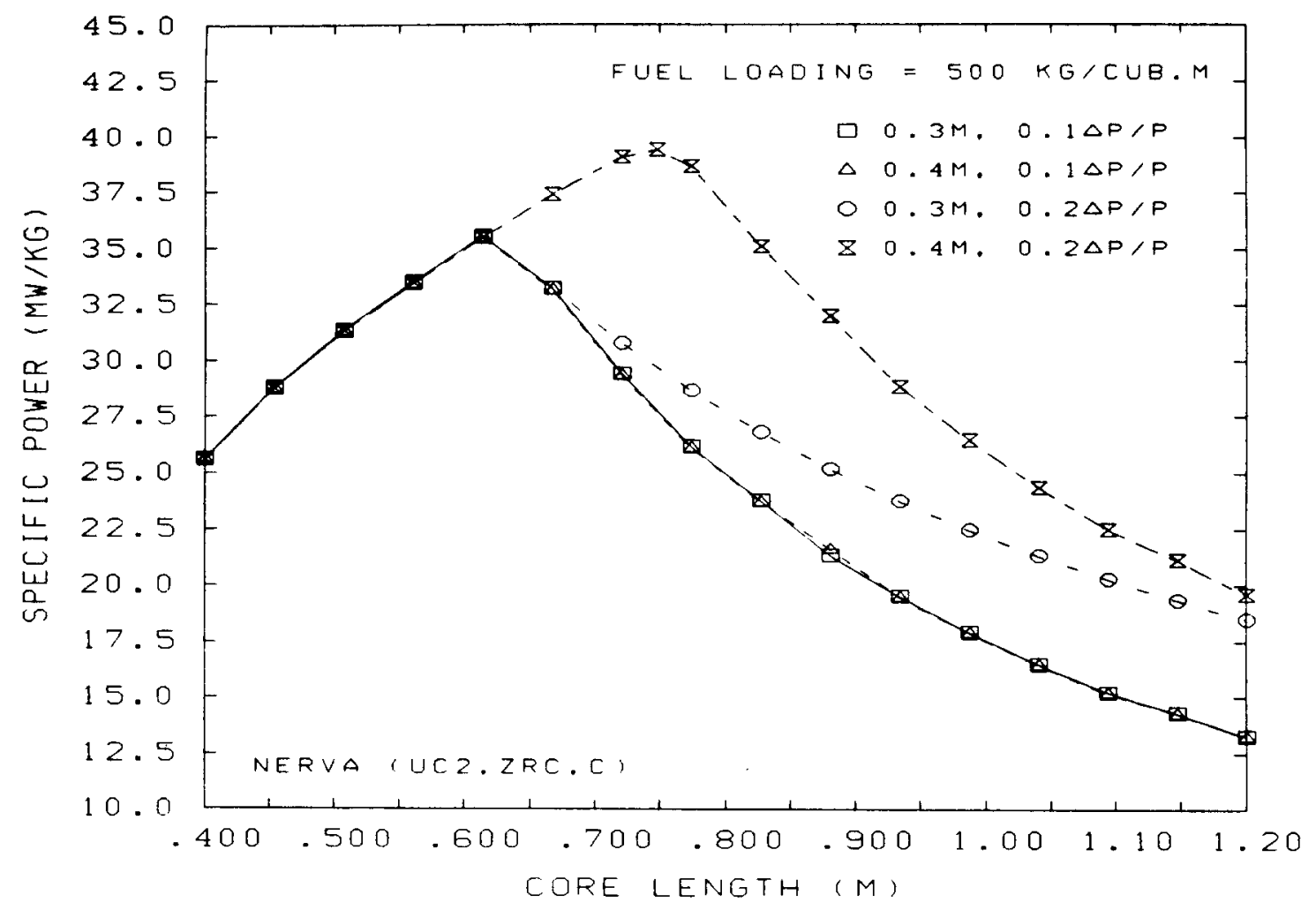

Figure 4.1.3 Effect of Mach Number and Pressure Drop Fraction on Specific Power (NERVA)

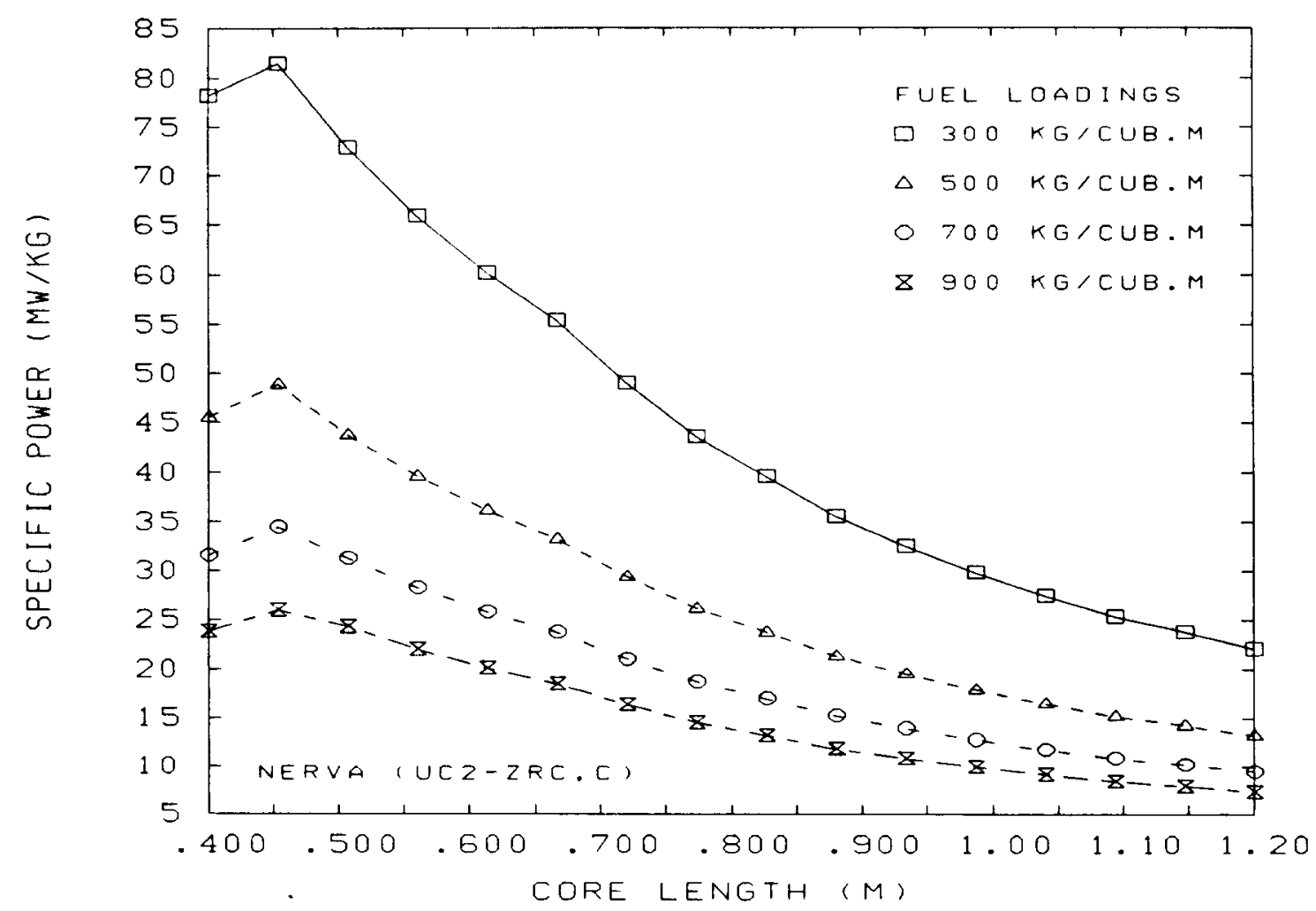

Figure 4.1.4 Specific Powers for NERVA Concept (UC ${ }_{2}-\mathrm{ZrC}, \mathrm{C}$ ) 


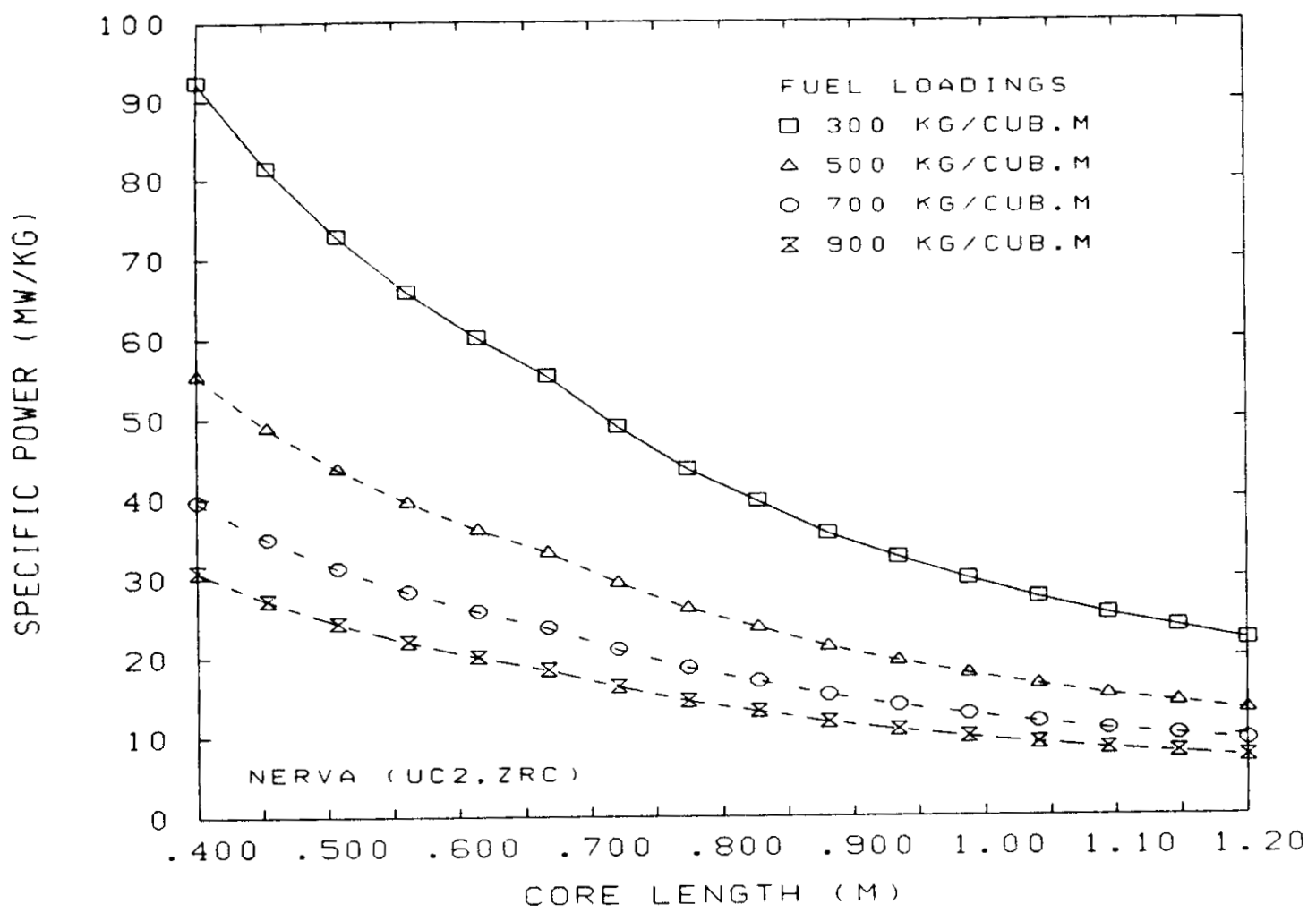

Figure 4.1.5 Specific Powers for NERVA Concept. $\left(\mathrm{UC}_{2}, \mathrm{ZrC}\right)$ 


\subsection{PLUTO}

Three variations of the PLUTO concept [6] were investigated. The geometry for these concepts is given in Table 4.2.1. The major difference between this geometry and that used for the NERVA concepts is that only one cooling channel per element is used. However, the channel volume fraction, defined as the total channel volume divided by the total element volume, is about the same for both concepts (about 30\%).

Table 4.2.1 PLUTO Geometric Data

$$
\begin{aligned}
& \text { Hexagon flat-to-flat width }-0.00683 \mathrm{~m} \\
& \text { Channel diameter }-0.004 \mathrm{~m} \\
& \text { Number of channels/element - } 1
\end{aligned}
$$

The first concept variation for PLUTO uses a $\mathrm{UO}_{2}$ fuel, BeO matrix composite core. The specific power results are shown in Figure 4.2.1 for this concept. The effect of the PLUTo geometry on the specific power is that the peak occurs at a greater core length. Using one channel per element results in less wall area per channel compared to using 19 channels per element (as in NERVA). This reduces the specific power in the heat transfer limited region but increases it in the hydraulic-limited region for the concept. The effects of increasing the maximum allowed Mach number and pressure drop fraction are similar to that observed for NERVA and are shown in Figure 4.2.2.

An additional set of calculations was performed for this concept in which the channel diameter was varied. (The hexagon width was changed for each channel diameter to maintain the channel volume fraction equal to 0.30 to maintain structural integrity.) The results of these calculations are shown in Figure 4.2.3. Increasing the diameter reduces the specific power in the heat transfer limited region while decreasing the diameter reduces the specific power in the hydraulic-limited region. Obviously, choosing the optimum channel diameter depends on the core length, which can only be determined in conjunction with criticality and control considerations. However, with respect to heat removal, it is apparent that using many small diameter channels is better for shorter cores and that using a few large diameter channels is better for longer cores.

The second PLUTO concept variation uses a $U C_{2}$ fuel, graphite matrix composite core. This is essentially the same as the second NERVA concept except for the geometry. The specific power for this concept is shown in Figure 4.2.4. Because this concept is similar to NERVA, comparing this to Figure 4.1.4 
shows the effect of changing the geometry from 19 small channels per element to one large channel per element. As expected, the effect is to increase the specific power for the larger values of core length.

The third PLUTo concept uses a core that is a composite of $\mathrm{UB}_{4}$ fuel and $\mathrm{B}_{4} \mathrm{C}$ matrix material. Because of the poor coriductivity of this material, the specific powers are relatively low and are heat transfer limited over the core length of interest, as shown in Figure 4.2.5. 


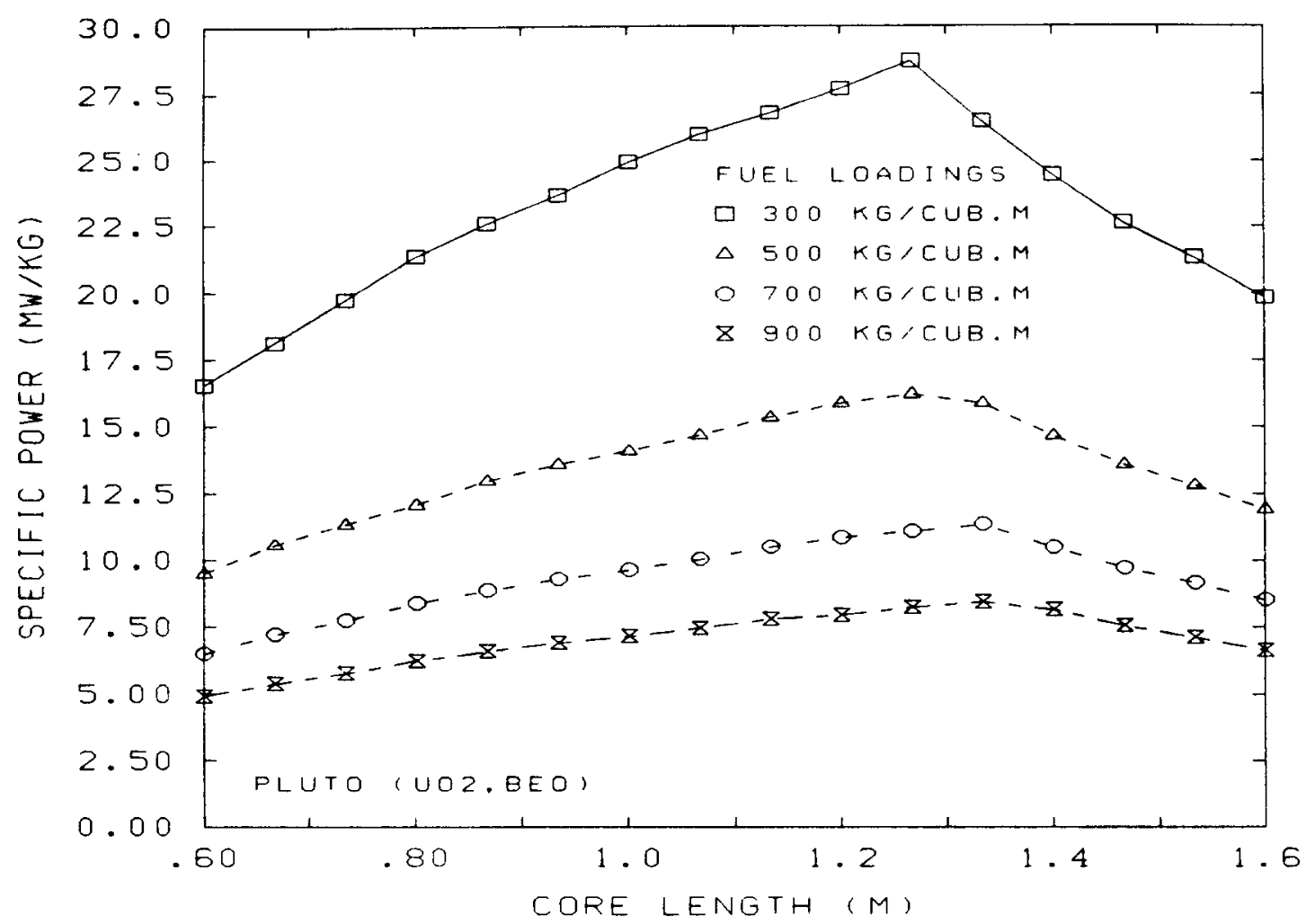

Figure 4.2.1 Specific Powers for PLUTO Concept $\left(\mathrm{UO}_{2}, \mathrm{BeO}\right)$

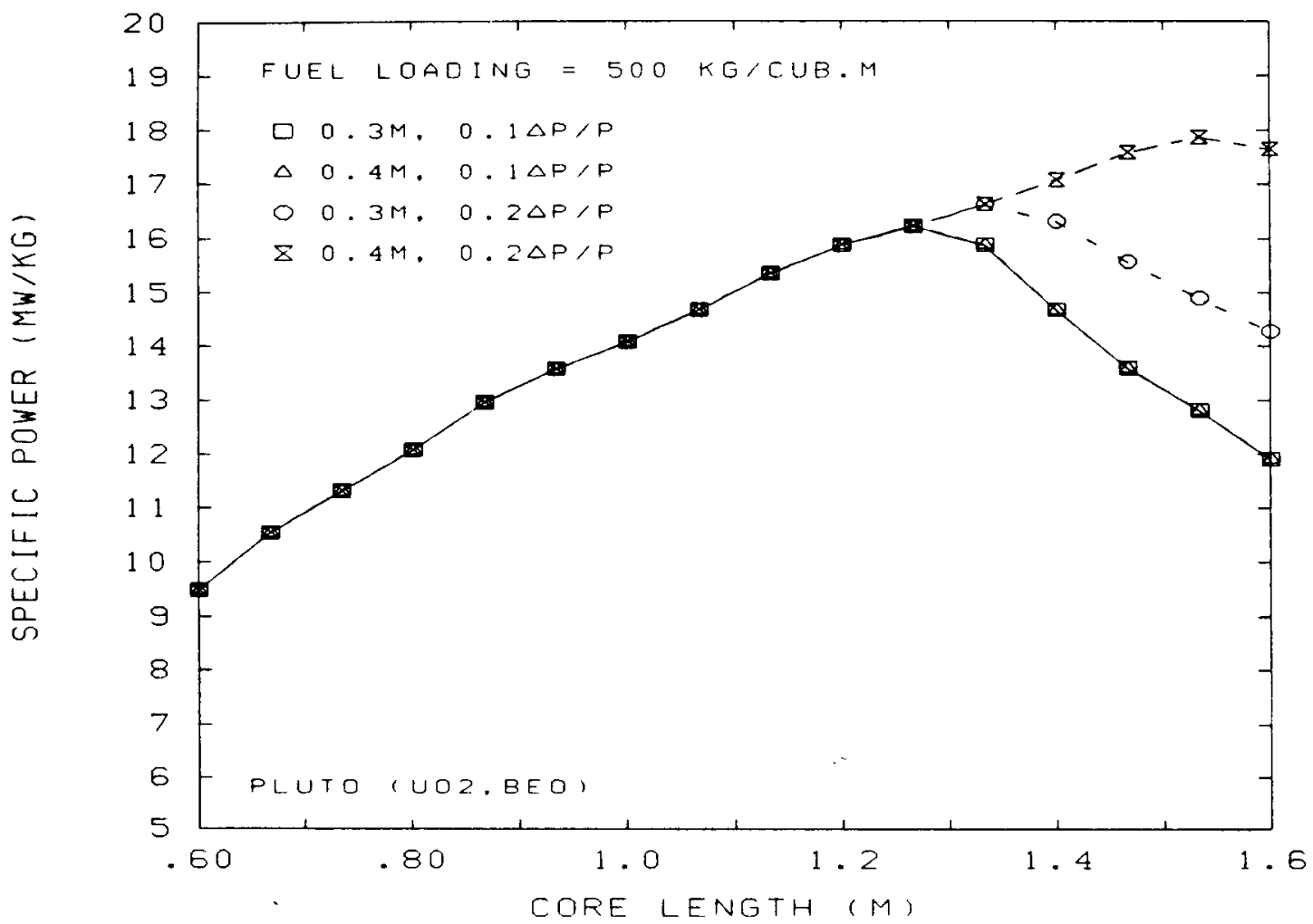

Figure 4.2.2 Effect of Mach Number and Pressure Drop Fraction on Specific Power (PLUTO) 


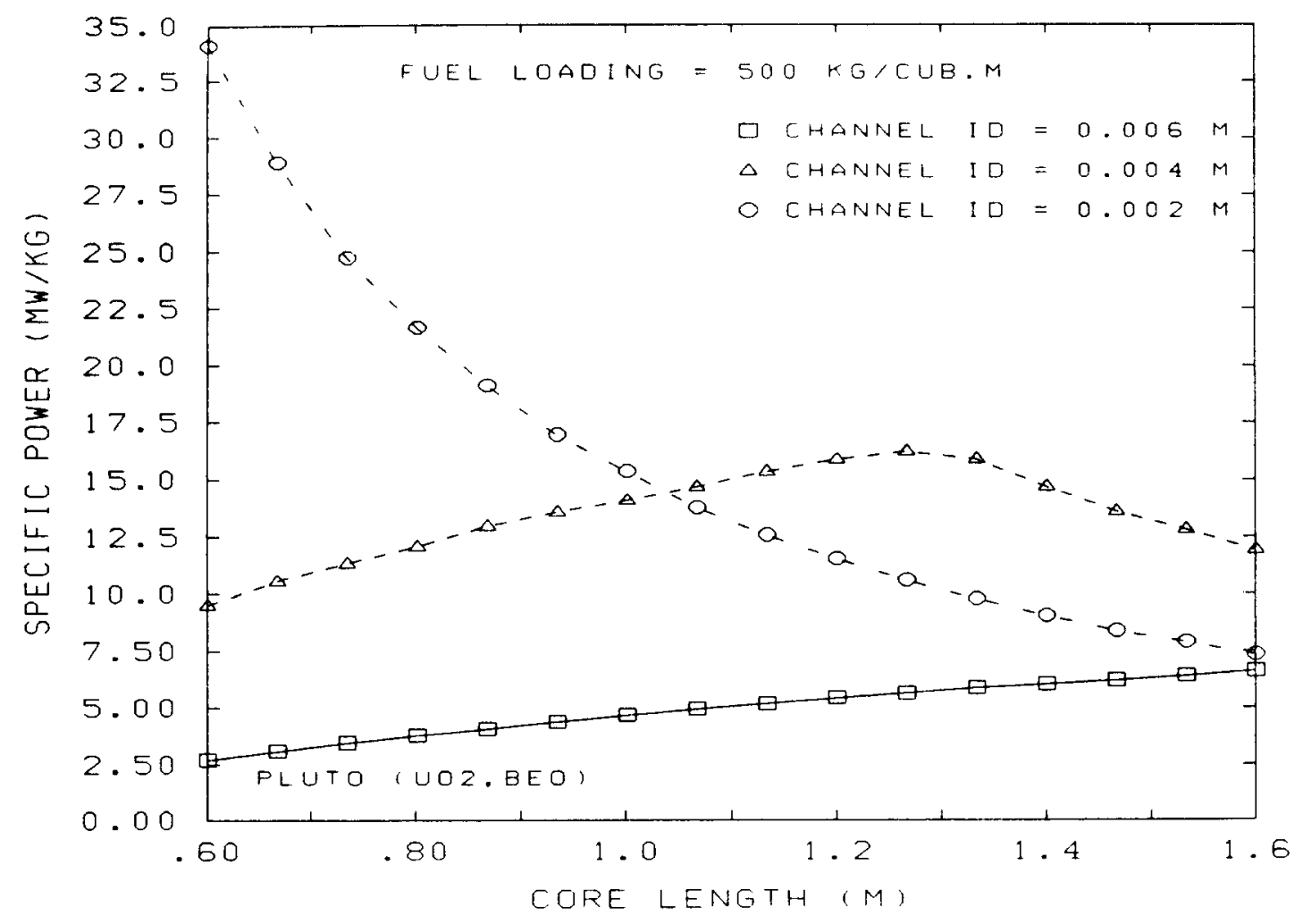

Figure 4.2.3 Effect of Channel Diameter (PLUTO)

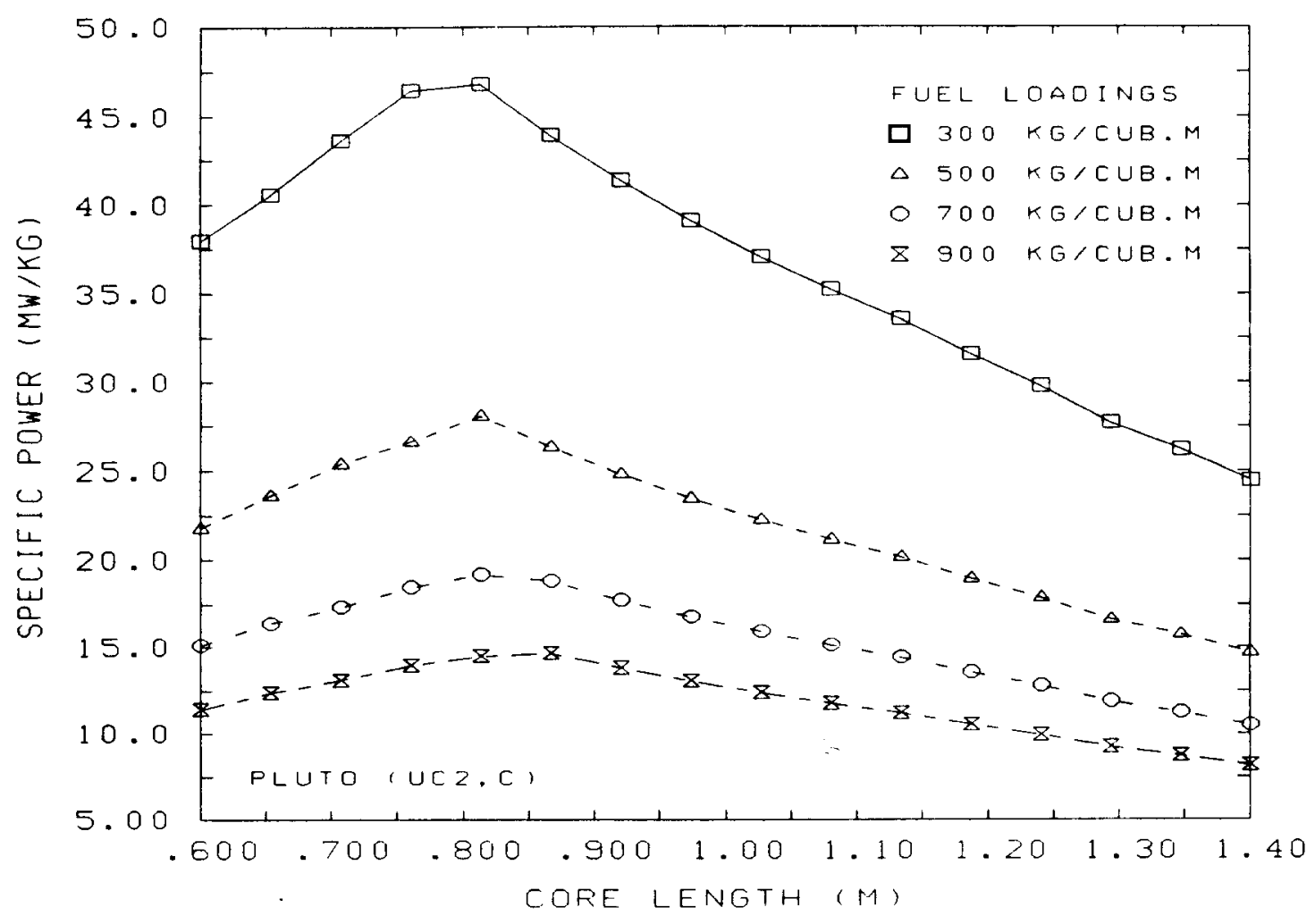

Figure 4.2.4 Specific Powers for PLUTO Concept $\left(\mathrm{UC}_{2}, \mathrm{C}\right)$ 


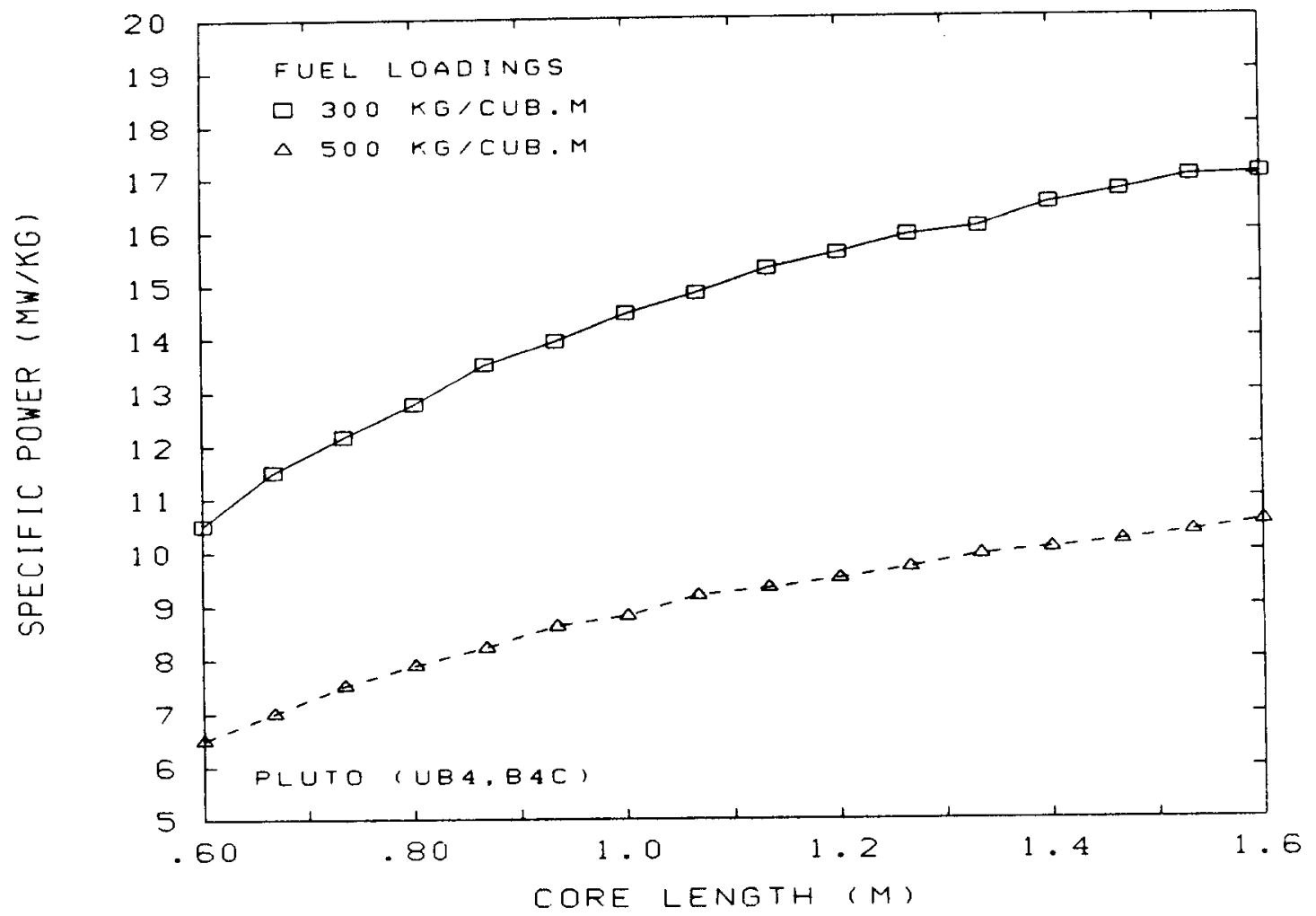

Figure 4.2.5 Specific Powers for PLUTO Concept $\left(\mathrm{UB}_{4}, \mathrm{~B}_{4} \mathrm{C}\right)$ 


\subsection{CERMET}

The final concept evaluated is a derivative of the 710 reactur [7] that used a core comprised of a ceramic fuel and a metai matrix material, referred to as a CERMET. The advantage of such a material is its very high thermal conductivity. The CERMET investigated is made of $\mathrm{UO}_{2}$ fuel dispersed as coated pellets in a tungsten matrix. The coating is also tungsten. An alternative to tungsten is molybdenum, but, because its thermal conductivity is very similar to that of tungsten, specific power calculations were performed only for the tungsten CERMET concept.

The geometric data for the 710 CERMET core is given in Table 4.3.1. Based on this data, the channel volume fraction for the 710 core is only 0.154 , compared to 0.30 for both NERVA and PLUTO. It is not known why such a low volume fraction was used; therefore, specific power calculations for both channel volume fractions were performed. (Also note that the pellet diameter is smaller than the pellet diameter used for NERVA.) The results are shown in Figure 4.3.1. (The fuel loadings used for these calculations are very high because, based on criticality calculations, the very high density of the matrix material results in an unacceptably low fuel-to-moderator ratio for lower fuel loadings.) As the figure shows, increasing the volume fraction to 0.30 appreciably increases the specific power. This same favorable increase can be realized for the other concepts provided structural integrity can be maintained at the higher volume fractions.

Table 4.3.1 CERMET Geometric Data

Hexagon flat-to-flat width $-0.03622 \mathrm{~m}$

Channel diameter - $0.00343 \mathrm{~m}$

Number of channels/element - 19

Fuel pellet diameter - $0.0001 \mathrm{~m}$

coating thickness - $0.00005 \mathrm{~m}$ 


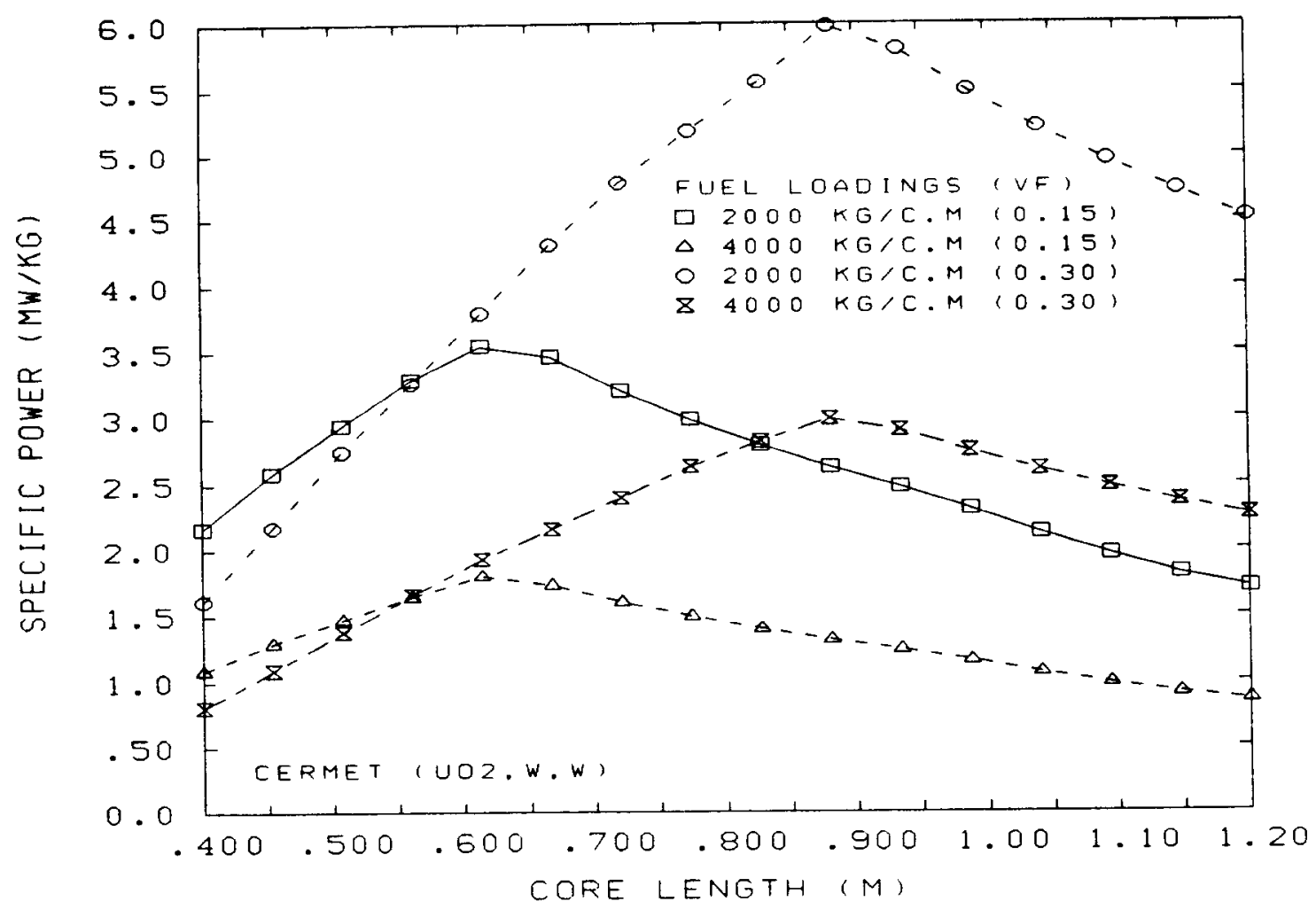

Figure 4.3.1 Specific Powers for CERMET Concept 


\subsection{SUMMARY OF PARAMETRIC CALCULATIONS}

Figure 4.4.1 shows the specific power for the three different concepts and their variations (for a $500 \mathrm{~kg} / \mathrm{m}^{3}$ fuel loading). This set of curves can not really be used for comparing specific powers among the various concepts because they do not reflect the criticality aspects associated with the different fuel loadings, core lengths, and fuel and matrix materials. However, they do provide an indication of what geometric parameter would have to be changed to improve the specific power in either the heat transfer or hydraulic-limited regions. For example, The NERVA concepts offer very good heat transfer characteristics but poor hydraulic characteristics with respect to specific power. To improve the hydraulic characteristics (at the expense of the heat transfer characteristics) it would be necessary to use fewer channels of larger diameter. This would shift the specific power peak to the right. The PLUTO concept that uses $\mathrm{UB}_{4}$ and $\mathrm{B}_{4} \mathrm{C}$ would require the exact opposite change. That is, it would be necessary to use more channels of smaller diameter to increase the specific power in the heat transfer limited region.

All of the concepts analyzed had the same basic geometry; i.e., a group of hexagonal elements with a certain number of channels formed within each element for coolant flow. It would therefore be possible to "redesign" (without consideration for structural integrity) all of the concepts in order to optimize the specific power with respect to channel diameter and number. Thus, with respect to thermal hydraulic performance, the only parameters that distinguish one concept from another are the thermal conductivity and the maximum operating temperature. However, it may not be possible to take advantage of a materials higher conductivity or temperature capability due to the imposed hydraulic limits. Whether or not a higher conductivity or temperature will be of benefit can only be determined after considering the criticality and control aspects of the concept. 


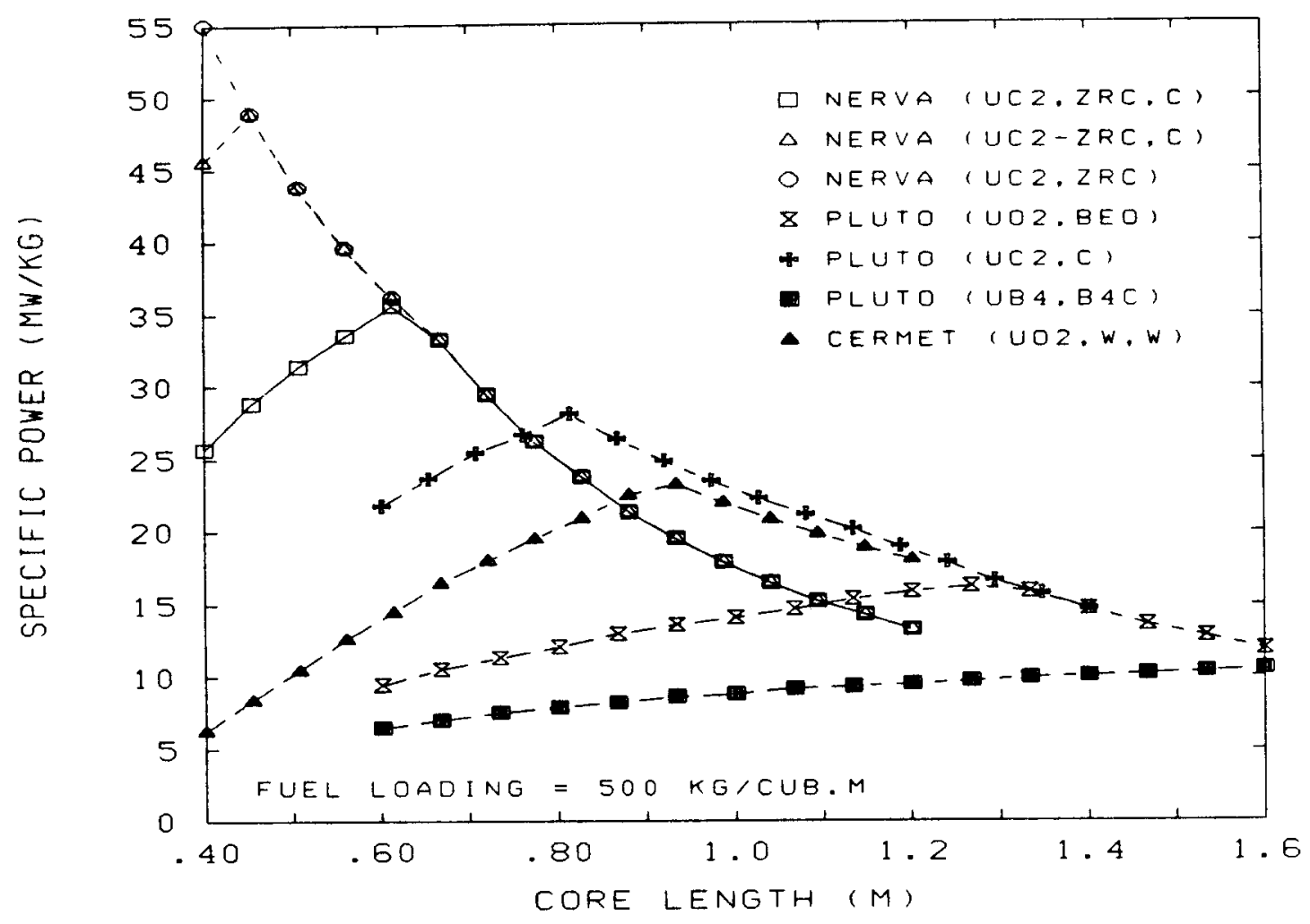

Figure 4.4.1 Specific Powers for All Concepts 


\subsection{SUMMARY AND CONCLUSIONS}

A computer program has been written to determine the maximum specific power for prismatic-core reactors as a function of maximum allowable fuel temperature, core pressure drop, and coolant velocity. The prismatic-core reactors consist of hexagonally shaped fuel elements grouped together to form a cylindrically shaped core. A gas coolant (either helium or hydrogen) flows axially through circular channels within the elements and the fuel is dispersed within the solid element (matrix) material either as a composite or in the form of coated pellets. Different coolant, matrix, coating, and fuel materials can be selected to represent different prismatic-core concepts. The computer program allows the user to divide the core into any arbitrary number of axial levels to account for different axial power shapes. An option in the program allows the automatic determination of the core height that results in the maximum specific power.

This program provides a simple means for evaluating and comparing the specific power of various prismatic-core concepts. The program is written such that additional material properties can easily be added if desired. Various input parameters allow the program user to specify different heat transfer and hydraulic constraints along with different core geometries. Results from the program also provide information that can be useful in the redesign of the concept to take better advantage of the heat transfer characteristics of the various core materials. 


\subsection{REFERENCES}

1. M. M. El-Wakil, NUCLEAR POWER ENGINEERING, McGraw-Hill, 1962 .

2. Glasstone and Sesonske, NUCLEAR REACTOR ENGINEERING, Van Nostrand Reinhold, 1967.

3. Incropera and DeWitt, FUNDAMENTALS OF HEAT TRANSFER, 1981.

4. "Nuclear Engine Definition Study Preliminary Report," Volume II - Supporting Studies, LA-5044-MS, September, 1972.

5. "A Design Study of Low Power, Light Weight Rover Reactors," W. L. Kirk, Los Alamos National Laboratory, LA-3642-MS, August 1966.

6. "Tory IIC Reactor Test Report," edited by Harry L. Reynolds, October 12,1964 .

7. "710 High Temperature Gas Reactor Summary Report," GEMP-600, General Electric. 


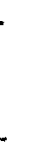


APPENDIX - COMPUTER PROGRAM LISTING

$A-1$ 
C PROGRAM TO DEIERMINE MAXIMUM SPECIFIC POWER FOR A REACTOR

C COMPRISED OF HEXAGONAL FUEL ELEMENTS (SUCH AS NERVA)

C INPUT: UNIT 5

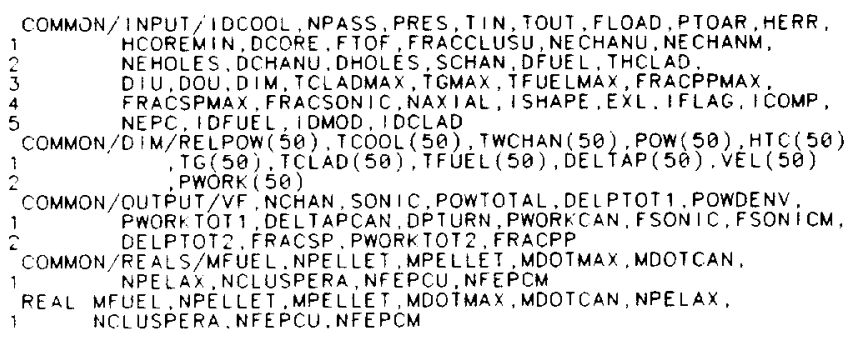

$\operatorname{READ}(5,1)$ NO

FORMAT (1) 1 )

READ $\{5, *\}$ IDCOOL

READ $5, *\{$ IOMOD

READ 5,* IDCLAD

REAO $5, *$ NPASS

READ 5 * * PRE

READ 5 * * IN

READ $5, *$ FLOAD

READ 5 * * PTOAR

READ 5 " HCORE

READ 5 ; * HCOREMIN

READ $5, *$ DCORE

READ 5, * FRACCLUSU

READ 5 , NEPC

READ $5, *$ NFEPCU

READ 5 * N NFEPCM

READ * NECHANU

READ 5 " : NE HOEES

READ (5,*) DCHANU

READ * OHOLES

READ 5 ; DFUEL

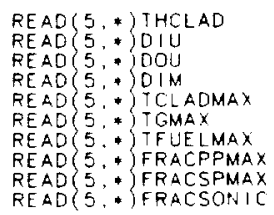




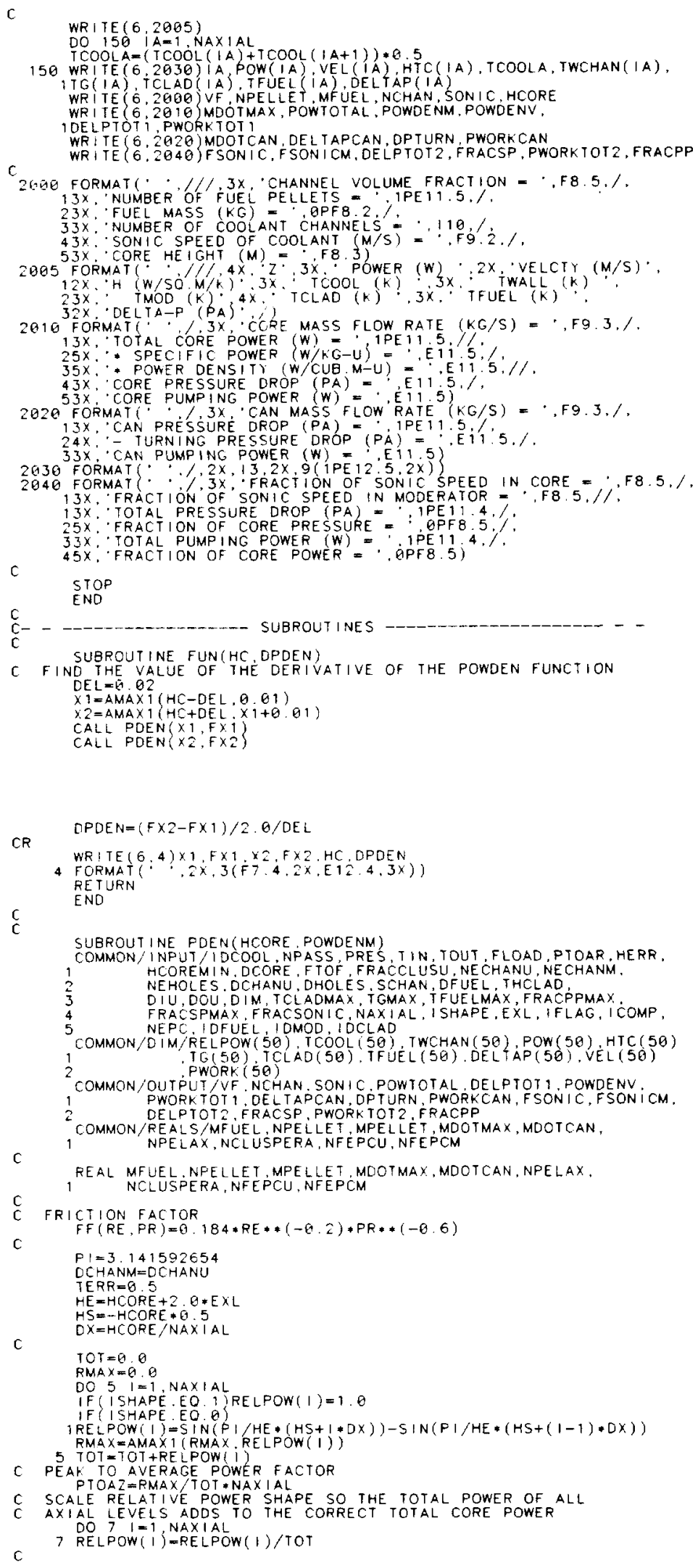

TOr $=8.0$$$
\text { RMA }
$$

C PEATTOAZ PMAXYTOT * NAXIAL

C SCALE RELATIVE POWER SHAPE SO THE TOTAL POWER OF ALL

AXIAL LEVELS ADDS TO THE CORRECT TOTAL CORE POWER

7 RELPOW( 1 i) $=$ RAXLPOW (1)/TOT

$c$ 
C CALCULATE CHANNEL FLOW AREA AND WALL AREA

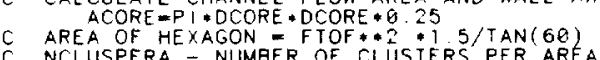

C NCLUSPERA - NUMEER OF CLUSTERS PER AREA OF CORE NCLUSPERA $=1 . \theta /(N E P C * 0.866025 * F$ TOF *FTOF) NCLUSTUENCLUSPERA*FRACCLUSU*ACORE

A CLLUSTM=NCLUSPERA* (1 O-FRACCLUSU) *ACORE

NFEPCU IS NUMBER OF FUELEO ELEMENTS UNMOO CLUSTER NFEPCU IS NUMBER OF FUELEO ELEMENTS/UNMOO CLUSTER NECHANU * NFEPCU $N C H A N M=N C L U S T M * N E C H A N M * N F E P C M$ NCHAN=NCHANU+NCHANM ACHAN=P1*DCHANU*DCHANU* $25 * N C H A N U+P 1 * D C H A N M * D C H A N M * B .25 * N C H A N M$ WACHAN=PI *DCHANU *HCORE * NCHANU+PI *DCHANM *HCORE * NCHANM

C SINGLE AND DOUBLE PASS ACANU $=P$ I *DOU*DOU*0. 25*NCLUSTU* (NEPC-NFEPCU) TMANEHOLES

C EFFECTIVE CHANNEL ANO CAN HYDRAUL IC DIAMETERS WFC $=$ WACHAN / HCORE DCHAN=4 O*ACHAN/AMAX 1 (WPC, D. Q9Q83)

$W P=N C L U S T U * P 1 *(D O U+2 \cdot \theta * D I U)$

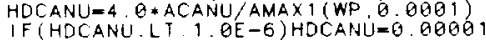

C FOR THREE PASSES

ACANU $1=P \mid * D I U * D I U * 0.25 *$ NCLUSTU* (NEPC-NFEPCU)

ACANU2 =ACANU-ACANU 1

WP $2=N C L U S T U * P 1 *(D O U+D I U)$ MOCANU2 4 G ACANU2 AMAX1 (WP2,0.0001)

C AREAS PER MOD AND UNMOD ELEMENTS
C NECHANM (NECHANU OF UNMOO ELEMENT)

APE $U=1, Q /$ (NEPC *NCLUSPERA)

$A P E M=A P E U$-NE CHANM/NECHAN

AETOT=APEU*NCLUSTU*NFEPCU +APEM*NCLUSTM*NFEPCM
C TOTAL VOL OF ALL ELEMENTS AVALLABLE FOR FUEL LOADING

VOLCORE = (AE YOT-ACHAN $) * H C O R E$

$\checkmark F=A C H A N / A E I O$

MFUEL $=F L O A D \cdot V O L C O R E$

C USE COLD (ROOM TEMPERATURE) DENSITY OF FUEL TO CALCULATE FUEL MASS CALL DENS ITY (300.0, 1OFUEL, OENFUEL)

MPELLET $=V O L P E L L E T$ ODENFUE NPELLET TME UEL/MPELLET

C CALCULATE MASS OF MODERATOR IN FUELED ELEMENTS

CALL DENSITYI 390 O. IDMOD, DENMOD

GMASS=DENMOO* (VOLCORE-MFUEL/DENFUEL)

C CALCULATE SONIC VELOCITY OF COOLANT AT CORE ENTRANCE ANO EXIT

(WM IS COOLANT MOLECULAR WE IGHT)

$W M=4.0$

IF ( I DCOOL EO. 2 ) WM=2 .

CALL CSUBPCOOL ( T IN, 1OCOOL, CSUBPCI)

CALL CSUBPCOOL

CALL DENCOOL PRES, TN, 1 COOL, DENCI)

GAMCOOL =CSUBPCI/(CSUBPC $1-8314,5 / \mathrm{WM}$ )

SONIC $1=$ GAMCOOL $/$ WM*8314.5*T|N)*0.5

GAMCOOL $=$ CSUBPCO $/(C S U B P C O-8314.5 / \mathrm{WM})$ SONICO $=(G A M C O O L / W M * 83 ; 4.5 *$ TOUT $) * 0.5$

$C$ MAXIMUM SONIC VELOCITY

NLET SONIC VELOCITY AS MAXIMUM ALLOWED

$V E L M A X=F R A C S O N I C$ * SON $|C|$

SONICESONICI

$x \rightarrow$ DENCI

I LOC $=1$

VELMAX =FRACSON $\mid C *$ SON ICO

SONICESONICO

$C=V E L M A X * D E N C O$

C ENDIF

DO $9100 \quad I V=1,390$

ON MAXIMUM ALLOWED VELOCITY (G = VEL DDEN)

MDOTMAXIX

(CSUBPCO+CSUEPCI)*Q.5*(TOUT-TIN)

POWPELLET = POWFUEL/NPELLET

POWOENM=POWTOTAL MFUEL

C BECH: STEPPING IHROUGH EACH AXIAL ZONE TO DETERMINE COOLANT. CLAD,

AND FUEL IEMPERATURES

GUESS FOR AZIAL ZONE COOLANT TEMPERATURE INCREASE

$T I=($ TOUT-TIN) NNAXIAL

$D \times P=0.0$

$I G G=0.0$
$T C L=0.0$

DELPTOT $1=0.0$

PWORKTOTI=O.0 


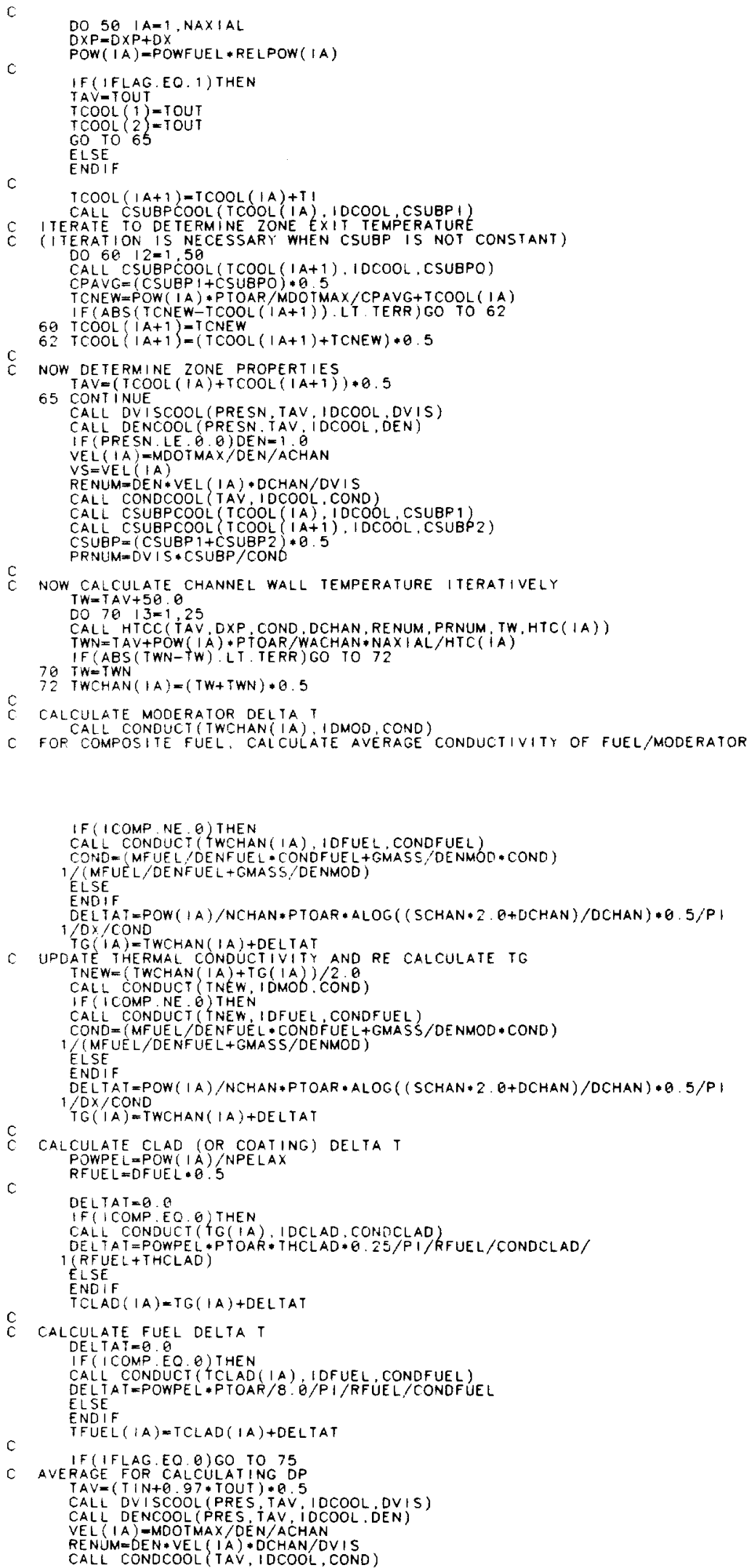

IF ( I COMP. NE O) THEN

CALL CONDUCT ( TWCHAN( IA), IDFUEL, CONDFUEL)

- CONDFUEL+GMASS/DENMOD*COND

1 (MFUEL/DENFUEL + GMASS/DENMOD)

ELSE

DELTAT=POW ( IA)/NCHAN*PTOAR * ALOG ( (SCHAN - 2. E+DCHAN)/DCHAN)*0.5/P

$1 / D X / C O N D$

C UPDATE THERMAL CONDUCTIYITY AND RE CALCULATE TG

TNEWE (TWCHAN (IA) +TG ( IA) $/ 2$.
CALL CONDUCT

IF ( I COMP. NE. O) THEN

CALL CONDUCT (INEW, I DFUEL, CONDFUEL)

COND= (MFUEL/DENFUEL * CONDFUEL+GMASS/DENMOD*COND)

1 ( (MFUEL/DENFUE L + GMASS/DENMDD)

ELSE

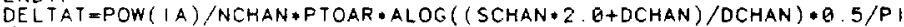

$1 / O X / C O N D$

C CALCULATE CLAD (OR COATING) DELTA T

POWPEL $=P O W($ I $)$ /NPELAX

DELTAT $=0 . E$
IFCICOMP.EO

IF (ICOMP.EO O) THEN

CALL CONDUCT (TC IA , IDCLAD CONDCLAD)

OAR* THCLAD:G. 25/PI/KFUEL/CONDCLAD/

ELSE

$T C L A D(I A)=T G(1 A)+D E L T T A T$

$\stackrel{c}{c}$

CALCULATE FUEL DELTA T

DELTAT=O.

IF (I COMP.EO O) THEN

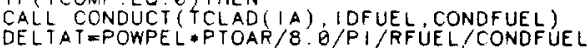

DELTAT

TFUEL ( IA) $=T C L A D(\mid A)+D E L T A T$

IF IFLAG. EO O) GO TO 75

CALL DVISCOOL (PRES TAV, IOCOOL DVIS)

CALL DENCOOL (PRES, TAV, IOCOOL.DEN)

VEL (IA) =MDOTMAX.OEN /ACHAN

CALL CONDCOOL $(T A V$, IDCOOL, COND) 
CALL CSUBPCOOL (TAV, IDCOOL, CSUBP)

C DETERM INE PRESSURE DROPS ANO PUMP WORK

75 CONTINUE

$F=F F$ (RENUM, PRNUM

DELTAP ( IA) $=F * D X / O C H A N * D E N * 0,5 * V E L(I A) * V E L(I A)$

PWORK (IA)=DELTAP (IA) A ACHAN*VEL (IA)

DELPTOT $1=$ DELPTOT 1 +DELTAP ( IA)

C DETERMINE MAXIMUM TEMPERATURES CONSIDERING ALL ZONES

TGG=AMAX 1 (TGG, TG( IA)

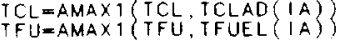

PRE SN=PRESN-DELTAP (IA)

50 CONTINUE

IF(NPASS.GT.1)GO TO 110

FOR SINGLE PASS FLOW

IRST CALCULATE PWORK FOR CANM

MOOTCAN $=0$.

DELTAPCAN=

OPTURN=Q1.O

CALL DVISCOOL (PRES, TIN, IDCOOL, DVIS)

CALL CONDCOOL (TIN, IDCOOL, COND)

CAL CSUBPCOOL (T IN IOCOOL CSUAP

PRNUM=DVIS * CSUBP COND

C MUSTIITERATE TO DETERMINE VELOCITY IN CANS

$V E L M I=0.8 * V E L M A X$

DO $80 \quad 14=1,15$

RENUM=QIEN*VELMI*DIM/OV IS

$F=F F$ (RENUM, PRNUM)

源

82 VELMI $=$ (VELMINEW+VELMI)*0 5

MDOTCAN=MDOTCAN+DEN*VELM *ACANM

C NOW REPEAT FOR HOLES

$V E L M H=V E L M$

DO $90 \quad 15=1,15$

RENUM=DEN*VELMH*DHOLE $\$ / O V I S$

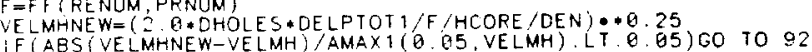

$90 . V E L M H=V E L M H N E W$

MDOTCAN=MDOTCAN+DEN*VE LMH* AHOLES
PWOFKCAN=PWORK CAN+DELPTOT 1 * AHOLES $V$ ELMH

C ANO FINALLY FOR UNMODERATEO CANS

VELU $=V E L M I$

DO PQA $16=1,15$

RENUMM=DEN*VELU*HDCANU/OVIS

$F=F F$ (RENUM, PRNUM)

IF IABSIVELUNEW-VELU I AMAX1(A G5, VELU). LT.0.05)GO TO 102

$19 Q V E L U=V E L U N E W$

$10 \hat{A}$ VELU $=(V E L U N E W+V E L U) * \theta .5$

MOOTCAN=MDOTCANTDEN*VELU.ACANL

PWORKCAN=PWORKCAN+DELPTOT1. ACANU *VELU

C

CO TO 146

11 C CONT INUE

IF NPASS GT 2) 60 TO 129

MOOT TAN MOOTMAX

CALL DENCOOL (PRES, TIN, I DCOOL, DEN)

CALL DVISCOOL (PRES, TIN, IDCOOL, OVIS)

CALL CONDCOOL T IN IDCOOL, COND)

CALL CSUBPCOOL ( TIN, IDCO

PRIUUM=OVIS*CSUBP / COND

$D M L=(D I M / H D C A N U) * * 0.5$

DHUL= DHOLES/HDCANUT: 5 . 5 GOUAL

STT GUESS ASSUMING FN ARE EOUAL + AHOLES*DHU)

$\checkmark M=V U$ DMU

$V M=V U$ :DMU

REU $=D E N * V U * H D C A N U / D V I S$

$R E H=D E N * V H * D H O L E S / D V I S$

$F U=F F$ (REU. PRNUIM

$F M=F F$ REM. PRNUM

$F H=F F$ (REH.PRNUM

MAX

VULATEO

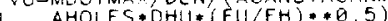

REU

$R E M=D E N * V M * D \mid M / O V I S$

REH=DEN*VH*DHOLES/DV/S

$\mathrm{FU}=\mathrm{FF}(\mathrm{REU}$. PRNUM $)$

$F M=F F(R E M$. PRNUM

$F H=F F(R E H, P R N U M)$

$V M=V U * D M U *(F U / F M) * * 0.5$

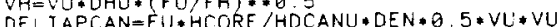

C ADD IN DP DUE TO TURNING LOSSES

$D F T U R N=F U * 50.0 * D E N * B \quad 5 * V U * V U$

DPTURN=FU*50. Q*DEN*B.5*

PWORH CAN $=D E$ TAPCAN* $A C A N U * V U+A C A N M * V M+A H O L E S * V H)$

$\checkmark M A X M=A M A X T(V U, V M, V H)$ 
120 CO TO 148

$c$
$c$

CONT INUE

C FOR THREE PASSES

MDOTCAN=MDOTMAX

CALL OENCOOL (PRES, TIN, IOCOOL, OEN)

CALL DVISCOOL (PRES, TIN, IDCOOL, DV

CALL CONDCOOL (T IN, IDCOOL, COND)

CALL CSUBPCOOL $(T I N$, IDCOD
PRNUM $=$ DV IS $*$ CSUBP $/$ COND

$F \cup 1=1 \cdot \theta$

$F \cup 2=1 \cdot \dot{\theta}$

$F H=1$ Q

DMU $=($ (FU1/O U+FU2/HDCANU2* (ACANU1/ACANU2)**2)/

$V U 1=$ MOOTMAX DEN/ (ACANU 1+ACANM+ OMU)

$V M=V U 1 \cdot D M U$

$\checkmark U 2=V U 1 * A C A N U 1 / A C A N U 2$

$V H=V M+A C A N M / A H O L E S$

REU $1=$ DEN*VUY $*$ D IU/DVIS
REU2 $=$ DEN*VU2*HDCANU2/OVIS

REU2-DEN*VU2* RDCANU2\%OVIS

$R E H=D E N * V H * D H O L E S / D V I S$

FU $1=F F$ (REU1, PRNUM

FUZ $=F F$, REUZ, PRNUM

$F M=F F$ (REM, PRNUM)

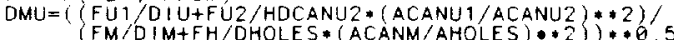

VU $1=M D O T M A X / O E N /($ ACANU $1+$ ACANM $*$ OMU)

$V M=V U 1 * D M U$

VU2=VU1 + ACANU1/ACANU2

$V H=V M * A C A N M / A H O L E S$

REU $1=D E N * V U 1+D 1 U / D V 1 S$
REU2 $=D E N * V U 2 * H D C A N U 2 / D V 15$

REM $=D E N+V M+D$ IM OAVIS

$R E H=D E N * V H * D H O L E S$ DVIS

$F \cup 1=F F$ (REU1, PRNUM

FU2 $=F F$ (REU2. PRNUM

$F M=F F$ (REM, PRNUM)

DELTAPCAN $1=F U 1 * H C O$

C ADD IN TAPCANZ=FUZ*HCORE/ HDCANUZ*DEN*Q.5*VUZ*VUZ

DPTURN1=FU1 $150.0 *$ DEN*Q., $5 * V U 1 * V U 1$

DPTUPNZ $=F U 2 * 56, Q * D E N * 0,5 * V U 2 * V U 2$

DELTAPCANTI DEL TAPCAN I +DP TURN

DELTAPCAN=DELTAPCAN $1+D E L T A P C A N 2$

PWORKCAN DELTAPCAN 1 ACANU1:VU1+

1 DELTAPCAN? ACANU2 VU2

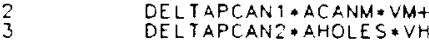

VMAXM=AMAX1 (VU1, VU2, VM, VH)

C 140 CONTINUE IN CAN DELTA P AND PUMP WORK TO THOSE OF CHANNELS

DELPTOT $Z=D E L P T O I 1+D E L T A P C A N$
PWORK TOT $\angle=$ PWORK TOTI +PWORKCAN

$c$

FRACPP=PWORK TOT2/POWTOTAL

FRACSP $=$ DELPTOT $2 / P R E S$

FSONICM=VMAXM/SONICI

F SON I CEVEL I LOC S SONIC
IF (IFLAG. EO. I)FSONIC=VS/SONIC

$C$ NOW CHECK IO SEE IF ANY LIMITS ARE EXCEEDED: IF SO THEN REDUCE $G$

AND REDO ALL CALCULATIONS

IF (TGG. LT. TGMAX. AND. TCL. LT. TCLADMAX AND TFU LT TFUELMAX. AND

IFRACPP. $L T$. FRACPPMAX AND FRACSP TT FRACSPMAX AND FSONICM LT

2FRACSONIC. AND. FSONIC.LT. FRACSONIC)

360 TO 1002

$\begin{array}{ll}1990 & G=G 9 \\ 1902 & C O N T I N U E\end{array}$

RETURN
ENO

C

SUBROUTINE XINT (HCOREMAX, HCOREMIN, H1, H2, FH1, FHZ)

IF HCOREMIN IS NEGATIVE. CALCULATE POWDEN FOR HCORE BETWEEN

HCOREMIN AND HCOREMAX INCREMENTED BY DELX

$\mathrm{OX}=0.4$

$H=H C O R E M I N$

$H 2=H 1+D X$

UN $(\mathrm{H} 1, \mathrm{FH} 1)$

5 CALL FUN(H2,FHZ)

$I=I I+1$
IF (FH1 FH2.LE.O.O)RETURN

$\mathrm{H} 1=\mathrm{H} 2$

$H 2=H 2+D X$

$H=A M I N 1(H 2, H C O R E M A X)$

I $(H 1, G E . H 2) T H E N$

$\mathrm{H} 1=\mathrm{H} 2$ 


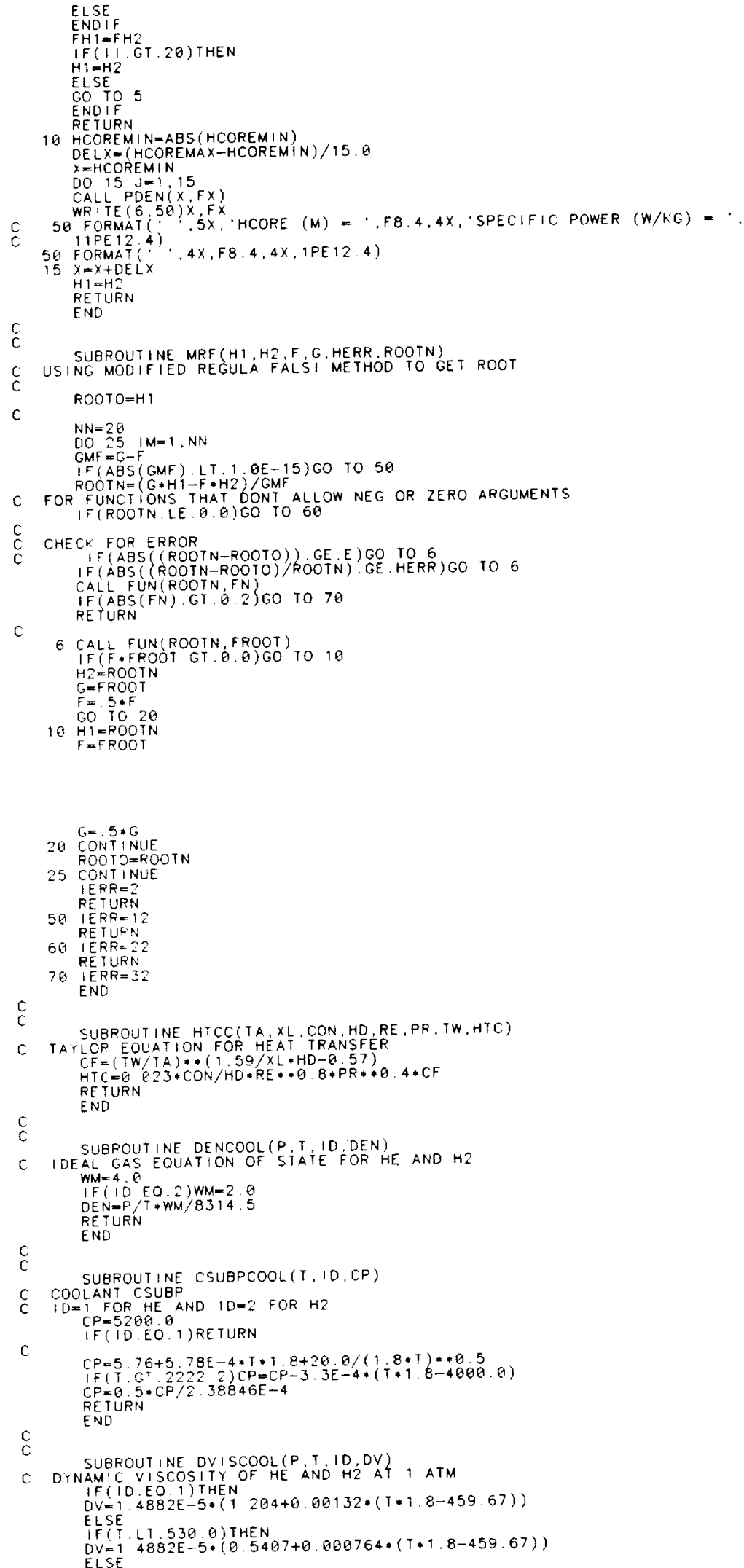




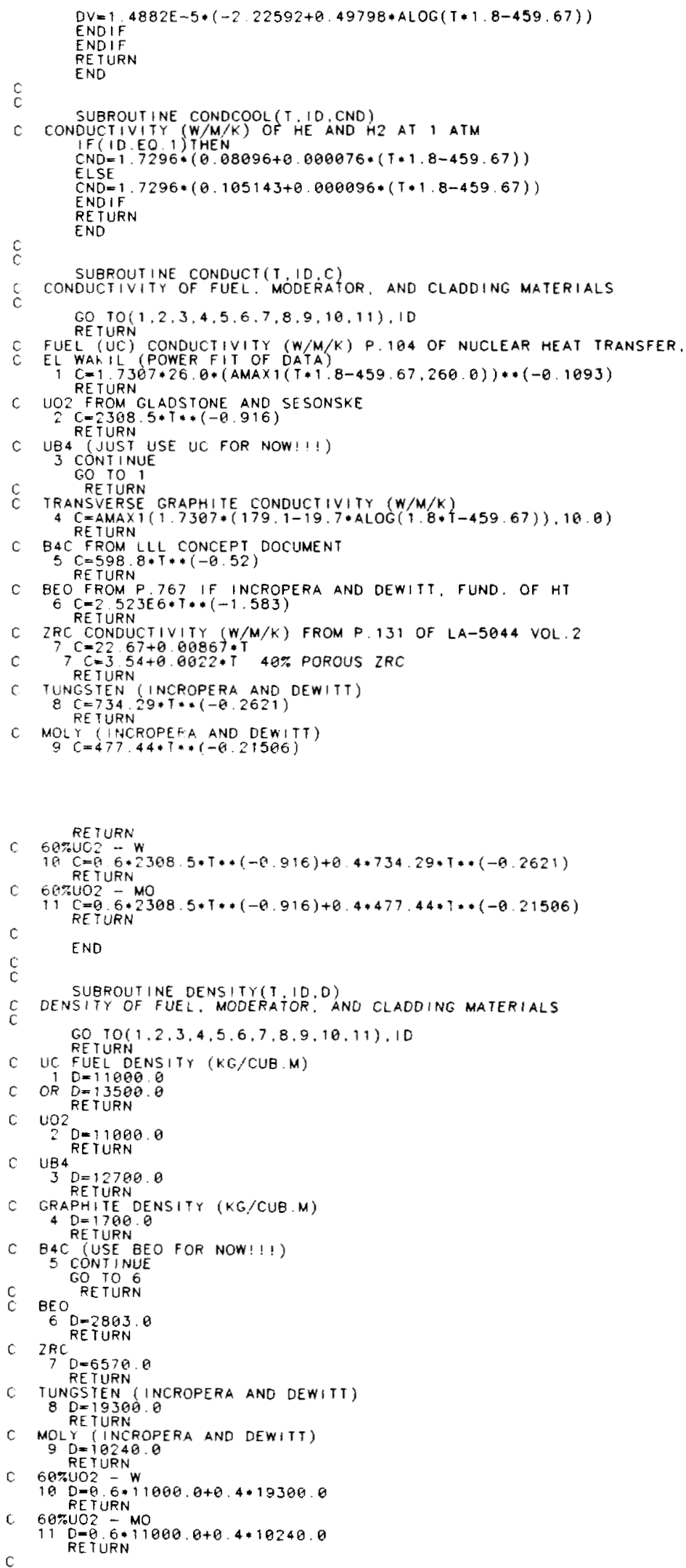




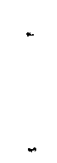


DISTRIBUTION

AFAT/SAS

Fort Walton Beach, FL 32542

Attn: Capt. Jerry Brown

AFISC/SNAR

Kirtland Air Force Base

New Mexico 87117

Attn: Lt. Col. J. P. Joyce

AF Astronautics Laboratory/LKCJ

Edwards Air Force Base

California 93523

Attn: G. Beale

AF Astronautics Laboratory/LKCJ

Edwards Air Force Base

California 93523

Attn: F. Meade

AF Astronautics Laboratory/LKCJ

Edwards Air Force Base

California 93523

Attn: Lt. R. Henley

AF Astronautics Laboratory/LKCJ

Edwards Air Force Base

California 93523

Attn: Major E. Houston

AFWAL/AA

Wright-Patterson AFB

Ohio 45433

Attn: Dick Renski

AFWAL/POOS

Wright-Patterson AFB

Ohio 45433

Attn: E. B. Kennel

AFWAL/POOC-1

Bldg. 450

Wright-Patterson AF Base

ohio 45433

Attn: R. Thibodeau

AFWAL/POO

Aeronautical Laboratory

Wright-Patterson AFB

Ohio 45433

Attn: w. Borger 
AFWAL/POOA

Aeronautical Laboratory

Bldg. 18

Wright-Patterson AFB

Ohio 45433

Attn: P. Colegrove

AFWAL/POOC-1

Aeronautical Laboratory

Bldg. 450

Wright-Patterson AFB

Ohio 45433

Attn: D. Massie

AFWAL/POOC-1

Aeronautical Laboratory

Wright-Patterson AFB

ohio 45433

Attn: C. Oberly

AFWAL/POOC-1

Aeronautical Laboratory wright-Patterson AFB

ohio 45433

Attn: T. Mahefky

AFWAL/POOS

Wright-Patterson AFB

Ohio 45433

Attn: J. Beam

AFWAL/POOC-1

Power Components Branch

Wright Patterson AFB

Ohio 45433-6563

AFWAL/POOC

Aeronautical Laboratory

Bldg. 18

Wright-Patterson AFB

ohio 45433

Attn: Major Seward

AFWL/AFSC

Kirtland Air Force Base

New Mexico 87117

Attn: M. J. Schuller

AFWL/AW

Kirtland AFB

New Mexico 87117

Attn: D. Kelleher 
AFWL/AWYS

Kirtland Air Force Base

New Mexico 87117

Attn: Lt. Col. Jackson

AFWL/AWYS

Kirtland Air Force Base

New Mexico 87117

Attn: Major D. R. Boyle

HQ AFSPACECOM/XPXIS

Peterson Air Force Base

Colorado 80914-5001

Attn: Lt. Col. F. Lawrence

HQ USAF/RD-D

washington, DC 20330-5042

Attn: Maj. P. Talty

Aerospace Corporation

P. O. Box 9113

Albuquerque, NM 87119

Attn: $w$. Zelinsky

Aerospace Corporation

P. O. Box 9113

Albuquerque, NM 87119

Attn: $w$. Blocker

Aerospace Corporation

P. O. Box 9113

Albuquerque, NM 87119

Attn: M. Firmin

Aerospace Corporation

P. O. Box 92957

El Segundo, CA 90009

Attn: P. Margolis

Air Force Center for studies and Analyses/SASD

The Pentagon, Room ID-431

Washington, DC 20330-5420

Attn: $W$. Barattino, AFCSA/SASD

Air Force Foreign Technology Div. TQTD

Wright-Patterson AFB

Ohio 45433-6563

Attn: B. L. Ballard 
Air Force Foreign Technology Div. TQTD

Wright-Patterson AFB

Ohio 45433-6563

Attn: K. W. Hoffman

Air Force Space Technology Center SWL

Kirtland AFB, NM 87117-6008

Attn: Capt. M. Brasher

Air Force space Technology Center SWL

Kirtland AFB, NM 87117-6008

Attn: J. DiTucci

Air Force Space Technology center SWL

Kirtland AFB, NM 87117-6008

Attn: Capt. E. Fornoles

Air Force space Technology Center TP

Kirtland AFB, NM 87117-6008

Attn: M. Good

Air Force Space Technology Center XLP

Kirtland AFB, NM 87117-6008

Attn: A. Huber

Air Force Space Technology Center SWL

Kirtland AFB, NM 87117-6008

Attn: $S$. Peterson

ANSER Corp.

Crystal Gateway 3

1225 Jefferson Davis Highway \#800

Arlington, VA 22208

Attn: K. C. Hartkay

Argonne National Laboratory

9700 S. Cass Avenue

Argonne, IL 60439

Attn: S. Bhattacharyya

Argonne National Laboratory

9700 S. Cass Avenue

Argonne, IL 60439

Attn: D. C. Fee 
Argonne National Laboratory

$9700 \mathrm{~S}$. Cass Avenue

Argonne, IL 60439

Attn: K. D. Kuczen

Argonne National Laboratory

9700 S. Cass Avenue

Argonne, IL 60439

Attn: R. A. Lewis

Argonne National Laboratory

9700 S. Cass Avenue

Argonne, IL 60439

Attn: D. C. Wade

Auburn University

202 Sanform Hall

Auburn, AL 36849-3501

Attn: Dr. T. Hyder

Auburn University

231 Leach Center

Auburn, AL 36849-3501

Attn: F. Rose

Avco Research Laboratory

2385 Revere Beach Pkwy

Everett, Mass. 02149

Attn: D. W. Swallom

Babcock \& Wilcox

Nuclear Power Division

3315 Old Forest Road

P.O. Box 10935

Lynchburg, VA 24506-0935

Attn: B. J. Short

Battelle Pacific Northwest Lab. P. O. Box 999

Richland, WA 99352

Attn: J. O. Barner

Battelle Pacific Northwest Lab. P. O. Box 999

Richland, WA 99352

Attn: L. Schmid

Battelle Pacific Northwest Lab. P. O. Box 999

Richland, WA 99352

Attn: E. P. Coomes 
Battelle Pacific Northwest Lab Battelle Boulevard

Richland, WA 99352

Attn: B. M. Johnson

Battelle Pacific Northwest Lab. P. O. Box 999

Richland, WA 99352

Attn: W. J. Krotiuk

Battelle Pacific Northwest Lab. P. O. Box 999

Richland, WA 99352

Attn: R. D. Widrig

Boeing Company

P.O. Box 3999

MS $8 \mathrm{~K}-30$

Seattle, WA 98124-2499

Attn: A. Sutey

Boeing Company

Boeing Aerospace system

P.0. Box 3707

Seattle, WA 98124

Attn: K. Kennerud

Brookhaven National Laboratory P.O. Box 155

Upton, NY 11973

Attn: T. Bowden

Brookhaven National Laboratory P.O. Box 155

Upton, NY 11973

Attn: H. Ludewig

Brookhaven National Laboratory P.O. Box 155

Upton, NY 11973

Attn: W. Y. Kato

Brookhaven National Laboratory P.O. Box 155

Bldg. 701, Level 143

Upton, NY 11973

Attn: J. Powell

California Inst. of Technology

Jet Propulsion Laboratory

4800 Oak Grove Drive

Pasadena, CA 91109

Attn: V. C. Truscello 
California Inst. of Technology

Jet Propulsion Laboratory

4800 Oak Grove Drive

Pasadena, CA 91109

Attn: P. Bankston

California Inst. of Technology

Jet Propulsion Laboratory

4800 Oak Grove Drive

Pasadena, CA 91109

Attn: E. P. Framan

California Inst. of Technology

Jet Propulsion Laboratory

4800 Oak Grove Drive

Pasadena, CA 91109

Attn: L. Isenberg

California Inst. of Technology

Jet Propulsion Laboratory

4800 Oak Grove Drive

Pasadena, CA 91109

Attn: J. Mondt

DARPA

1400 Wilson Blvd.

Arlington, VA 22209

Attn: P. Kemmey

DCsCoN Consulting

4265 Drake Court

Livermore, CA 94550

Attn: D. C. Sewell

Defense Nuclear Agency

6801 Telegraph Road

Alexandria, VA 22310-3398

Attn: J. Farber/RAEV

DNA/RAEV

6801 Telegraph Road

Alexandria, VA 22310-3398

Attn: J. Foster

EG\&G Idaho, Inc./INEL

P.O. Box 1625

Idaho Falls, ID 83415

Attn: R. Rice 
EG\&G Idaho, Inc./INEL P.O. Box 1625

Idaho Falls, ID 83415

Attn: J. Dearien

EG\&G Idaho, Inc./INEL P.O. Box 1625

Idaho Falls, ID 83415

Attn: M. L. Stanley

EG\&G Idaho, Inc./INEL P.O. Box 1625

Idaho Falls, ID 83415

Attn: R. D. Struthers

EG\&G Idaho, Inc./INEL

P.O. Box 1625

Idaho Falls, ID 83415

Attn: J. F. Whitbeck

EG\&G Idaho, Inc./INEL

P.O. Box 1625

Idaho Falls, ID 83415

Attn: P. W. Dickson

EG\&G Idaho, Inc./INEL

P.O. Box 1625

Idaho Falls, ID 83415

Attn: J. W. Henscheid

Ford Aerospace Corporation

Aeronutronic Div.

Ford Road, P.O. Box A

Newport Beach, CA 92658-9983

Attn: V. Pizzuro

GA Technologies

P.O. Box 85608

San Diego, CA 92138

Attn: H. J. Snyder

GA Technologies

P.O. BoX 85608

San Diego, CA 92138

Attn: C. Fisher

GA Technologies

P.O. BoX 85608

San Diego, CA 92138

Attn: R. Dahlberg 
Garrett Fluid systems Co. P.O. Box 5217

Phoenix, AZ

Attn: Robert Boyle

General Electric Company

P. O. Box 8555

Astro Systems

Philadelphia, PA 19101

Attn: R. J. Katucki

General Electric NSTO

310 DeGuigne Drive

Sunnyvale, CA 90486

Attn: E. E. Gerrels

General Electric NSTO

310 DeGuigne Drive

Sunnyvale, CA 90486

Attn: H. S. Bailey

General Electric-sco

P. O. Box 8555

Astro Systems

Philadelphia, PA 19101

Attn: J. Chan

General Electric

P. O. Box 8555

Astro Systems

Philadelphia, PA 19101

Attn: J. Hnat

General Electric

P. O. Box 8555

Astro Systems

Philadelphia, PA 19101

Attn: R. D. Casagrande

General Electric

P. O. Box 8555

Astro Systems

Philadelphia, PA 19101

Attn: w. Chiu

Grumman Aerospace Corporation

M/S B20-05

Bethpage, NY 11714

Attn: J. Belisle 
Hanford Engineering Dev. Lab

Post office Box 1970

Richland, WA 99352

Attn: D. S. Dutt

House of Representatives Staff

Space and Technology Committee

2320 Rayburn Building

Washington, DC 20515

Attn: Tom weimer

Idaho National Engineering

Laboratory

P. O. Box 1625

Idaho Fall, ID 83414

Attn: W. H. Roack

Innovative Nuclear space Pwr. Inst. 202 NSC

University of Florida

Gainesvilie, FL 32611

Attn: N. J. Diaz

International Energy Assoc. Ltd.

1717 Louisiana NE

Suite 202

Albuquerque, NM 87110

Attn: G. B. Varnado

Lawrence Livermore National Lab. P. O. Box 808

Livermore, CA 94550

Attn: Lynn Cleland, MS L-144

Lawrence Livermore National Lab.

P. O. Box 808

Livermore, CA 94550

Attn: C. E. Walter, MS L-144

Los Alamos National Laboratory

P. O. Box 1663

Los Alamos, NM 87545

Attn: T. Trapp, MS-E561

Los Alamos National Laboratory

P. O. Box 1663

Los Alamos, NM 87545

Attn: R. Hardie, MS-F611 
Los Alamos National Laboratory P. O. Box 1663

Los Alamos, NM 87545

Attn: C. Bell, MS A145

Los Alamos National Laboratory P. O. Box 1663

Los Alamos, NM 87545

Attn: R. J. Leclaire

Los Alamos National Laboratory P. O. Box 1663

Los Alamos, NM 87545

Attn: S. Jackson, MS-F611

Los Alamos National Laboratory P. O. Box 1663

Los Alamos, NM 87545

Attn: J. Metzger

Los Alamos National Laboratory P. O. Box 1663

Los Alamos, NM 87545

Attn: C. W. Watson, MS-F607

Los Alamos National Laboratory P. O. Box 1663

Los Alamos, NM 87545

Attn: Don Reid, MS-H811

Los Alamos National Laboratory P. O. Box 1663

Los Alamos, NM 87545

Attn: R. Bohl, MS-K551

Los Alamos National Laboratory P. O. Box 1663

Los Alamos, NM 87545

Attn: D. R. Bennett

Los Alamos National Laboratory P. O. Box 1663

Los Alamos, NM 87545

Attn: W. L. Kirk

Los Alamos National Laboratory P. O. Box 1663

Los Alamos, NM 87545

Attn: M. Merrigan 
Los Alamos National Laboratory

P. O. Box 1663

Los Alamos, NM 87545

Attn: T. P. Suchocki

Los Alamos National Laboratory

P. O. Box 1663

Los Alamos, NM 87545

Attn: L. H. Sullivan

Martin Marietta Corp.

P. O. Box 179

Denver, Co 80201

Attn: R. Giellis

Martin Marietta Corp.

P. O. Box 179

Denver, CO 80201

Attn: R. Zercher

MSL8060

Massachusetts Institute of Technology

1328 Albany Street

Cabridge, MA 02139

Attn: J.A. Bernard

NASA Lewis Research Center

21000 Brookpark Road

Cleveland, OH 44135

Attn: Barbara McKissock, MS 301-5

NASA Lewis Research Center

21000 Brookpark Road

Cleveland, OH 44135

Attn: A. Juhasz, MS 301-5

NASA Lewis Research Center

21000 Brookpark Road

Cleveland, OH 44135

Attn: J. Smith, MS 301-5

NASA Lewis Research Center

21000 Brookpark Road

cleveland, OH 44135

Attn: H. Bloomfield, MS 301-5

NASA Lewis Research Center

21000 Brookpark Road

Cleveland, OH 44135

Attn: C. Purvis, MS 203-1 
NASA Lewis Research Center 21000 Brookpark Road

Cleveland, OH 44135

Attn: D. Bents, MS 301-5

NASA Lewis Research Center

21000 Brookpark Road

Cleveland, OH 44135

Attn: G. Schwarze, MS 301-2

NASA Lewis Research Center

21000 Brookpark Road

Cleveland, OH 44135

Attn: I. Myers, MS 301-2

NASA Lewis Research Center

21000 Brookpark Road

Cleveland, OH 44135

Attn: G. Schwarze, MS 301-2

NASA Lewis Research Center

21000 Brookpark Road

Cleveland, OH 44135

Attn: J. Sovie, MS 301-5

National Research Council

Energy Engineering Board Commission on Engineering and Technical systems

2101 Constitution Avenue

Washington, DC 20418

Attn: $R$. Cohen

Naval Research Laboratory

Washington, DC 20375-5000

Attn: R. L. Eilbert

Naval Research Laboratory

Washington, DC 20375-5000

Attn: I. M. Vitkovitsky

Naval space Command

Dahlgren, VA 22448

Attn: Commander R. Nosco

Naval Space Command

N5

Dahlgren, VA 22448

Attn: Maj. J. Wiley

Naval Space Command

Dahlgren, VA 22448

Attn: Mr. B. Meyers 
Naval Surface Weapons Center

Dahlgren, VA 22448-5000

Attn: R. Gripshoven-F12

Naval Surface Weapons Center Dahlgren, VA 22448-5000

Attn: R. Dewitt-F12

Naval Surface Weapons Center

White Oak Laboratory

Silver Springs, MD 20903-500

MC $R-42$

Attn: B. Maccabee

Nichols Research Corp.

2340 Alamo Street, SE

Suite 105

Albuquerque, NM 87106

Attn: $\mathrm{R}$. Weed

Oak Ridge National Laboratory

P. O. BoX Y

Bldg. 9201-3, MS-7

oak Ridge, TN 37831

Attn: J. P. Nichols

Oak Ridge National Laboratory P. O. BoX $Y$

Bldg. 9201-3, MS-7

Oak Ridge, TN 37831

Attn: D. Bartine

Oak Ridge National Laboratory P. O. Box X

Oak Ridge, TN 37831

Attn: H. W. Hoffman

Oak Ridge National Laboratory P. O. BoX Y

Bldg. 9201-3, MS-7

Oak Ridge, TN 37831

Attn: R. H. Cooper, Jr.

Oak Ridge National Laboratory P. O. BOX Y

Bldg. 9201-3, MS-7

Oak Ridge, TN 37831

Attn: J. C. Moyers 
Oak Ridge National Laboratory

P. O. BoX Y

Oak Ridge, TN 37831

Attn: M. Olszewski

Oak Ridge National Laboratory

P. O. BOX Y

Bldg. 9201-3, MS-7

Oak Ridge, TN 37831

Attn: M. Siman-Tov

Oak Ridge National Laboratory

P. O. BoX Y

Bldg. 9201-3, MS-7

Oak Ridge, TN 37831

Attn: F. W. Wiffen

RADC/OCTP

Griffiss AFB

New York 13441

Attn: R. Gray

Riverside Research Institute

1701 No. Ft. Meyers Drive

Suite 700

Arlington, VA 22209

Attn: J. Feig

Science Applications, Inc.

505 Marquette Avenue NW

Albuquerque, NM 87102

Attn: D. Buden

Science \& Engineering Associates

6301 Indian School Road, NE

Albuquerque, NM 87110

Attn: G. L. Zigler

SDI Organization

The Pentagon

Washington, DC 20301-7100

Attn: R. Verga

SDI Organization

The Pentagon

Washington, DC 20301-7100

Attn: R. Wiley

SDI/SLKT

The Pentagon

1717 H. st. NW

Washington, D. C. 20301

Attn: c. Northrup 


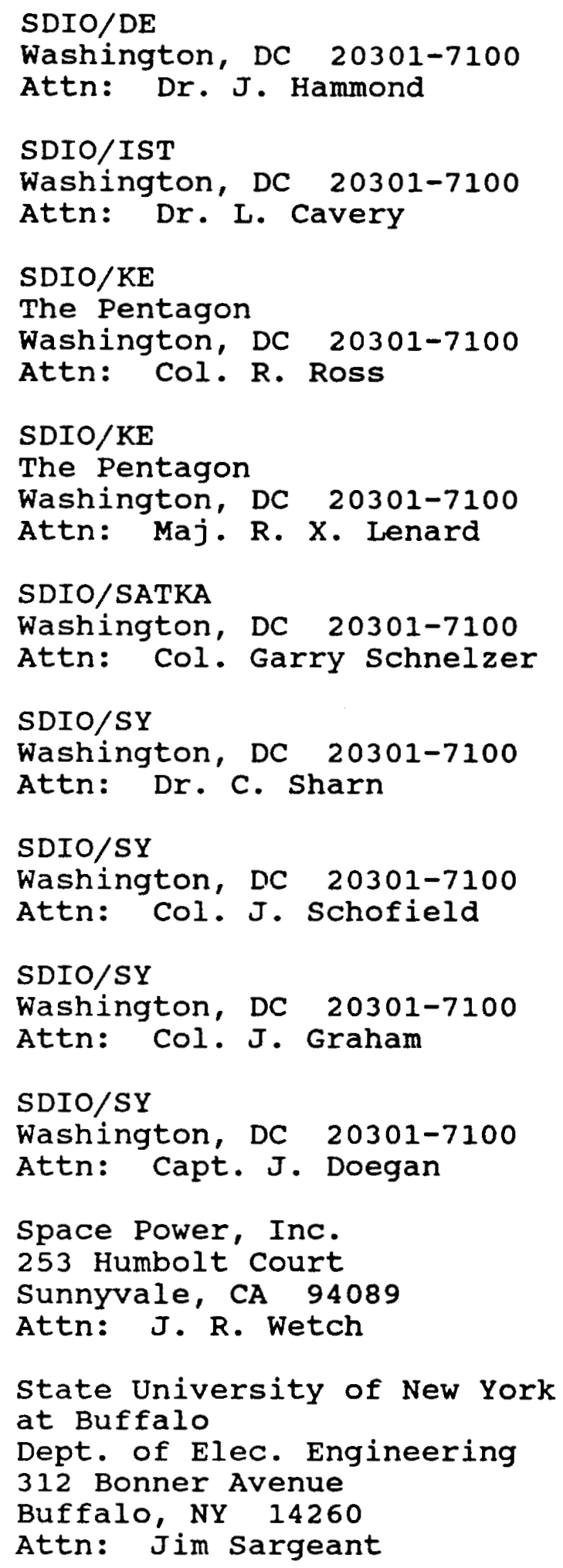




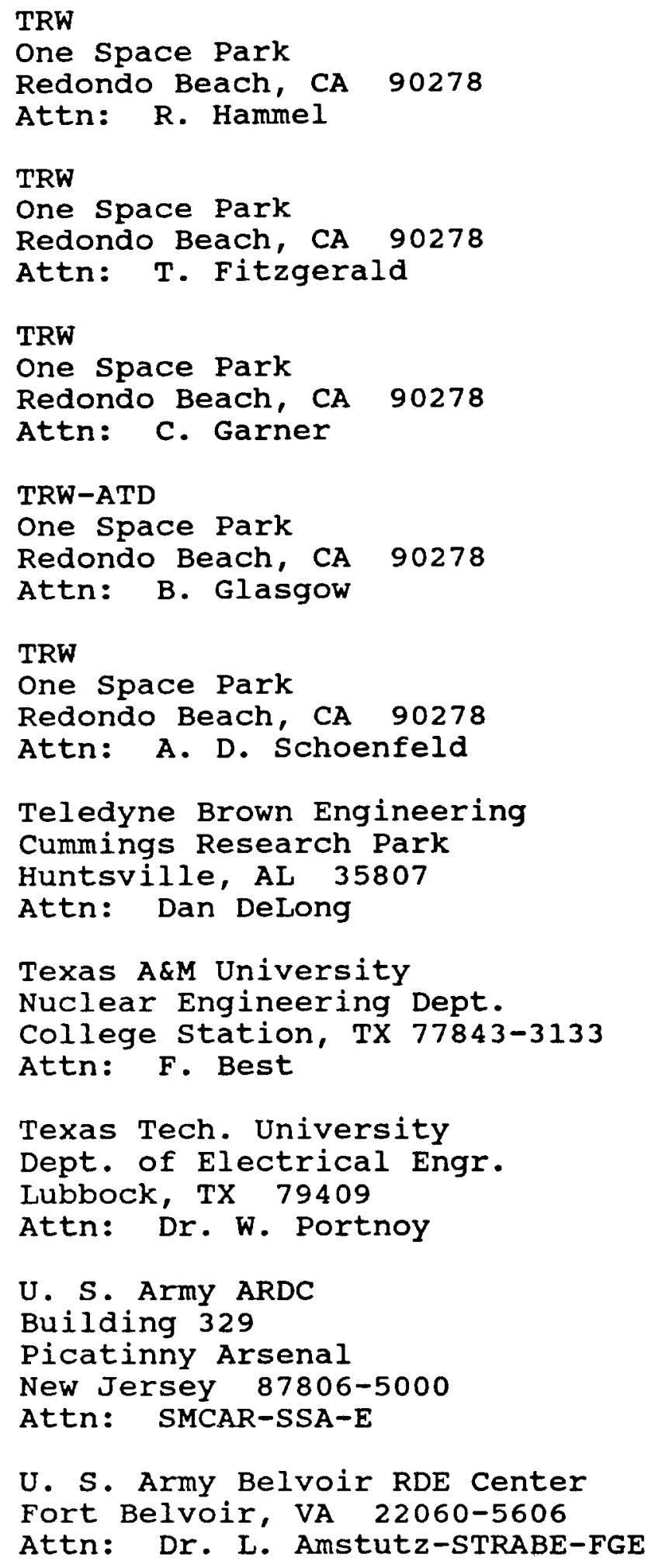


U. S. Army Lab. Com.

SLKET/ML

Pulse Power Technology Branch

Fort Monmouth, NJ 07703-5000

Attn: S. Levy

U. S. Army Lab. Com.

SLKET/ML

Pulse Power Technology Branch

Fort Monmouth, NJ 07703-5000

Attn: N. Wilson

U. S. Army Strategic Defense Com.

106 Wynn Drive

Huntsville, AL 35807

Attn: C. Cooper

U. S. Army Strategic Defense Com. 106 Wynn Drive

Huntsville, AL 35807

Attn: G. Edlin

U. S. Army Strategic Defense Com. 106 Wynn Drive

Huntsville, AL 35807

Attn: R. Hall

U. S. Army Strategic Defense Com. 106 Wynn Drive

Huntsville, AL 35807

Attn: E. L. Wilkinson

U. S. Army Strategic Defense Com. 106 Wynn Drive

Huntsville, $\mathrm{AL} 35807$

Attn: D. Bouska

U. S. Army Strategic Defense Com. 106 Wynn Drive

Huntsville, AL 35807

Attn: W. Sullivan

U. S. Army Strategic Defense Com. 106 Wynn Drive

Huntsville, AL 35807

Attn: $F$. King

U. S. Department of Energy

Chicago Operations office

9800 S. Cass Avenue

Argonne, IL 60439

Attn: J. L. Hooper 
U. S. Department of Energy NE/521 Germantown

washington, D. C. 20545

Attn: E. U. Kahn

U. S. Department of Energy

$\mathrm{NE}-521$

E419/GTN

Germantown, MD 20545

Attn: J. Warren

U. S. Department of Energy

NE-54

F415/GTN

Germantown, MD 20545

Attn: $E$. Wahlquist

U. S. Department of Energy

NE-521

Germantown, MD 20874

Attn: D. Bennett

U. S. Department of Energy

San Francisco Operations office

1333 Broadway Ave,

Oakland, CA 94612

Attn: J. K. Hartman

U. S. Department of Energy

SAN - ACR Division

1333 Broadway

Oakland, CA 94612

Attn: J. Krupa

U. S. Department of Energy

SAN - ACR Division

1333 Broadway

Oakland, CA 94612

Attn: $\quad W$. Lambert

U. S. Department of Energy

SAN - ACR Division

1333 Broadway

Oakland, CA 94612

Attn: J. Zielinski

U. S. Department of Energy

Pittsburgh Energy Tech. Center

P.O. Box 18288

Pittsburgh, PA 15236

Attn: G. Staats $(\mathrm{PM}-20)$ 
U. S. Department of Energy

$\mathrm{NE}-54$

washington, DC 20545

Attn: I. Helms

U. S. Department of Energy

Washington, DC 20545

Attn: W. Cook

U. S. Department of Energy

NE- 54

Washington, DC 20545

Attn: E. E. Hoffman

U. S. Department of Energy

Washington, DC 20545

Attn: J. Hooper

U. S. Department of Energy

washington, DC 20545

Attn: R. J. Hoyles

U. S. Department of Energy

washington, DC 20545

Attn: E. E. Lambert

U. S. Department of Energy

Washington, DC 20545

Attn: S. J. Lanes

U. S. Department of Energy

washington, DC 20545

Attn: $J$. O. Lee

U. S. Department of Energy

Washington, DC 20545

Attn: S. L. Samuelson

U. S. Department of Energy

washington, DC 20545

Attn: E. M. Richardson

U. S. Department of Energy

ALO/ETD

P.O. Box 5400

Albuquerque, New Mexico 87115

Attn: R. Holton 
U. S. Department of Energy

ALO/ETD

P.O. Box 5400

Albuquerque, New Mexico 87115

Attn: c. Quinn

U. S. Department of Energy/Idaho

785 DOE Place

Idaho Falls, ID 83402

Attn: P. J. Dirkmaat

United Technologies

International Fuel cells 195 Governor's Highway

South windsor, CT 06074

Attn: D. McVay

United Technologies

International Fuel cells

195 Governor's Highway

South windsor, CT 06074

Attn: J. L. Preston, Jr.

United Technologies

International Fuel cells

195 Governor's Highway

South windsor, CT 06074

Attn: J. C. Trocciola

University of Missouri - Rolla

220 Engineering Research Lab

Rolla, MO 65401-0249

Attn: A. S. Kumar

University of New Mexico

Chemical and Nuclear Engineering

Department

Albuquerque, NM 87131

Attn: M. El-Genk

University of Wisconsin

Fussion Technology Institute

1500 Johnson Drive

Madison, WI 53706-1687

Attn: Gerald Kukinski

W. J. Schafer Associates

1901 No. Ft. Myers Drive

Suite 800

Arlington, VA 22209

Attn: P. Mace 
W. J. Schafer Associates 1901 No. Ft. Myers Drive Suite 800

Arlington, VA 22209

Attn: $s$. Bassett

W. J. Schafer Associates 1901 No. Ft. Myers Drive Suite 800

Arlington, VA 22209

Attn: M. Nikolich

W. J. Schafer Associates 1901 No. Ft. Myers Drive Suite 800

Arlington, VA 22209

Attn: J. Crissey

W. J. Schafer Associates 2000 Randolph Road, SE \#205

Albuquerque, NM 87106

Attn: D. C. Straw

W. J. Schafer Associates 1901 No. Ft. Myers Drive Suite 800

Arlington, VA 22209

Attn: A. K. Hyder

Westinghouse Electric

P. O. Box 158

Madison, PA 15663-0158

Attn: J. Chi

Westinghouse

Advanced Energy Systems Division Manager, Space \& Defense Program Route 70, Madison Exit

Madison, PA 15663

Attn: J. F. Wett

Westinghouse

Advanced Energy Systems Division P.O. Box 158

Madison, PA 15663

Attn: Dr. J. W. H. Chi

Westinghouse R\&D

1310 Beulah Road

Bldg. 501-3Y56

Pittsburgh, PA 15235

Attn: J. R. Repp 
Westinghouse R\&D

1310 Beulah Road

Bldg. 501-3Y56

Pittsburgh, PA 15235

Attn: L. Long

Westinghouse R\&D

1310 Beulah Road

Bldg. 501-3Y56

Pittsburgh, PA 15235

Attn: Owen Taylor

Westinghouse Advanced Energy Systems Division

P.O. Box 158

Madison, PA 15663

Attn: G. Farbman

Westinghouse Hanford Company

P. O. Box 1970

Richland, WA 99352

Attn: D. S. Dutt

Westinghouse Hanford Company

P. O. Box 1970

Richland, WA 99352

Attn: B. J. Makenas 


$\begin{array}{ll}1140 & \text { P. Peercy } \\ 1200 & \text { J. P. Van Devender } \\ 1240 & \text { K. Prestwich } \\ 1248 & \text { M. Buttram } \\ 1270 & \text { R. Miller } \\ 1271 & \text { M. Clauser } \\ 1800 & \text { R. Schwoebel } \\ 1810 & \text { G. Kepler } \\ 1830 & \text { M. Davis } \\ 1832 & \text { W. Jones } \\ 1832 & \text { R. Salzbrenner } \\ 1840 & \text { R. Eagan } \\ 2110 & \text { R. Bair } \\ 2120 & \text { W. Dawes, Jr. } \\ 2140 & \text { C. Gibbon } \\ 2150 & \text { E. Graham, Jr. } \\ 2560 & \text { J. Cutchen } \\ 3141 & \text { S. A. Landenberger (5) } \\ 3151 & \text { W. L. Garner (3) } \\ 3154-1 & \text { C. H. Dalin (28) for DOE/DSTI } \\ 6400 & \text { D. McCloskey } \\ 6410 & \text { N. Ortiz } \\ 6420 & \text { J. Walker } \\ 6440 & \text { D. Dahlgren } \\ 6450 & \text { T. Schmidt } \\ 6500 & \text { A. W. Snyder } \\ 6510 & \text { W. Gauster } \\ 6511 & \text { L. Cropp (10) } \\ 6511 & \text { M. Edenburn } \\ 6511 & \text { D. Gallup } \\ 6511 & \text { S. Hudson } \\ 6511 & \text { A. Marshal1 (10) } \\ 6511 & \text { W. McCulloch } \\ 6511 & \text { R. Pepping } \\ 6511 & \text { F. Thome } \\ 6512 & \text { D. Ericson } \\ 8024 & \text { P. W. Dean } \\ 8400 & \text { R. Wayne } \\ 9000 & \text { R. Hagengruber } \\ 9010 & \text { W. C. Hines } \\ 9012 & \text { J. Keizur } \\ 9012 & \text { L. Connell } \\ 9012 & \text { R. Zazworski } \\ 9100 & \text { R. Clem } \\ 9110 & \text { P. Stokes } \\ 9140 & \text { D. Rigali } \\ & \end{array}$

